University of Nebraska - Lincoln DigitalCommons@University of Nebraska - Lincoln

2012

\title{
Historical Perspectives on AVHRR NDVI and Vegetation Drought Monitoring
}

Assaf Anyamba

National Aeronautics and Space Administration

Compton J. Tucker

National Aeronautics and Space Administration, compton.j.tucker@nasa.gov

Follow this and additional works at: http://digitalcommons.unl.edu/nasapub

Anyamba, Assaf and Tucker, Compton J., "Historical Perspectives on AVHRR NDVI and Vegetation Drought Monitoring" (2012). NASA Publications. 217.

http://digitalcommons.unl.edu/nasapub/217

This Article is brought to you for free and open access by the National Aeronautics and Space Administration at DigitalCommons@University of Nebraska - Lincoln. It has been accepted for inclusion in NASA Publications by an authorized administrator of DigitalCommons@University of Nebraska - Lincoln. 
Published in Remote Sensing of Drought: Innovative Monitoring Approaches, edited by Brian D. Wardlow, Martha C. Anderson, \& James P. Verdin (CRC Press/Taylor \& Francis, 2012).

This chapter is a U.S. government work and is not subject to copyright in the United States.

\section{Assaf Anyamba}

Universities Space Research Association \& Biospheric Sciences Laboratory

National Aeronautics and Space Administration

Goddard Space Flight Center

Greenbelt, Maryland

\section{Compton J. Tucker}

Hydrological and Biospheric Sciences Laboratory

National Aeronautics and Space Administration

Goddard Space Flight Center

Greenbelt, Maryland 


\title{
2 Historical Perspectives on AVHRR NDVI and Vegetation Drought Monitoring
}

\author{
Assaf Anyamba and Compton J. Tucker
}

\section{CONTENTS}

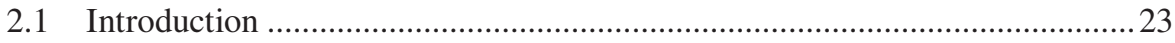

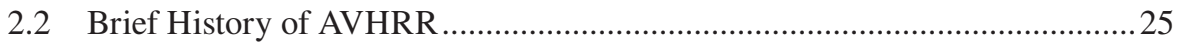

2.3 Normalized Difference Vegetation Index....................................................... 27

2.3.1 NDVI Derived from AVHRR Measurements .................................227

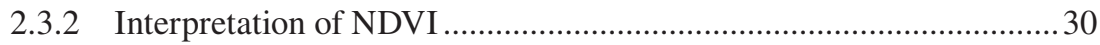

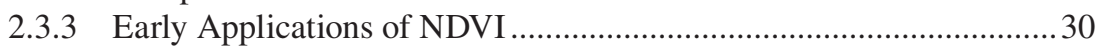

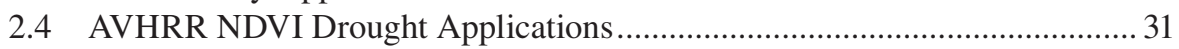

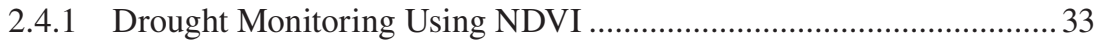

2.4.1.1 NDVI Anomalies ....................................................... 33

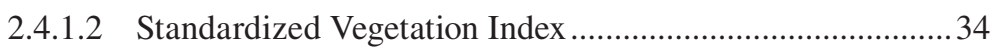

2.4.2 Drought Monitoring Using NDVI and Land-Surface Temperature ..... 34

2.4.2.1 Vegetation Condition Index ............................................... 34

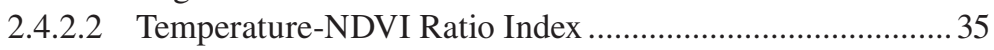

2.4.3 Limitations of NDVI as a Drought-Monitoring Tool ........................ 35

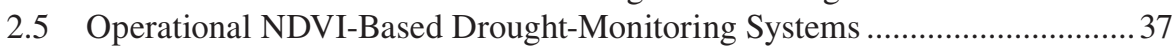

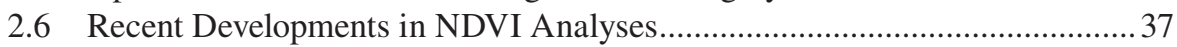

2.7 Instrumental Challenges and Next-Generation NDVI Sensors .....................40

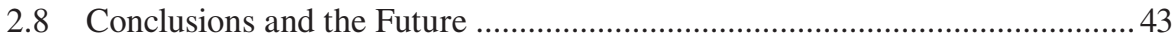

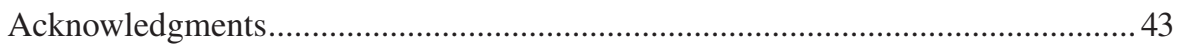

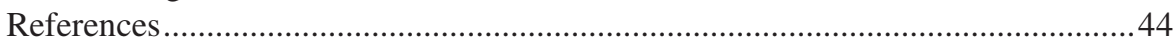

\subsection{INTRODUCTION}

Satellite measurements of the biosphere have now become common place in various aspects of large-scale environmental monitoring, including drought and crop monitoring. This was not the case until the launch of the Advanced Very High Resolution Radiometer (AVHRR) instrument on June 27, 1979, on board the first National Oceanic and Atmospheric Administration (NOAA) Advanced Television 
Infrared Observation Satellite (TIROS-N/NOAA-6) polar-orbiting satellite. Initially, the NOAA AVHRR satellites were designed to observe the earth's weather patterns: primarily cloud dynamics, vertical soundings of the atmosphere, and sea surface temperatures. Early studies on remote sensing of vegetation were focused on understanding seasonality. The vernal advancement and retrogradation of vegetation (e.g., spring green-up, summer abundance, and fall dry-down) was first studied over the north-south expanse of the U.S. Great Plains using data from the Earth Resources Technology Satellite (ERTS) Multi-Spectral Scanner (MSS) instrument (Rouse et al., 1974a,b). Rouse et al. (1974a) and others demonstrated that biophysical characteristics of vegetation over this rangeland and cropland region could be inferred from satellite spectral measurements despite solar zenith angle differences across a long latitudinal gradient (Deering et al., 1975). Rouse et al. (1974b) developed a difference ratio metric between the red and near-infrared (NIR) radiances over their sum to normalize the effects of the solar zenith angle. This derivation is based on the unique spectral response function of vegetated surfaces compared to other surface matter in the visible and NIR portion of the electromagnetic spectrum, as shown in Figure 2.1.

Spectral reflectances and radiances of green vegetation canopies in the red region of the electromagnetic spectrum are inversely related to in situ chlorophyll density because of photosynthetic chlorophyll absorption by vegetation in this band. In contrast, energy in the NIR region is scattered and reflected by the canopy structure

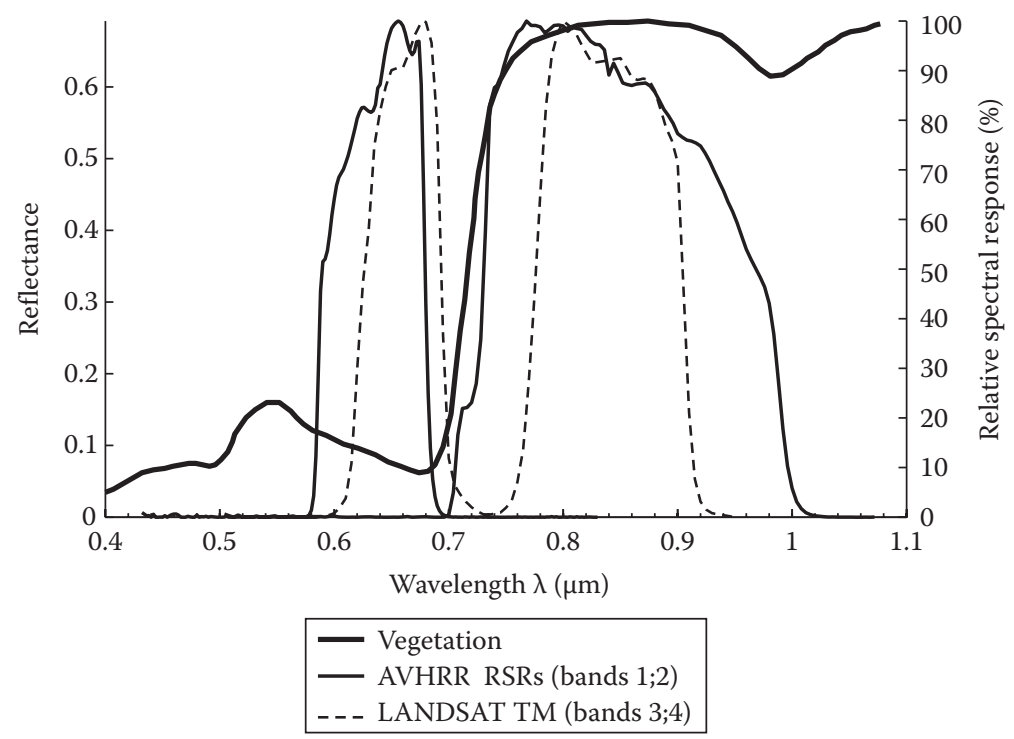

FIGURE 2.1 Spectral response curve of vegetation and the relative spectral response (RSR) of Landsat Thematic Mapper (TM) and AVHRR bands in the visible and infrared portions of the electromagnetic spectrum. This characteristic response pattern of vegetation has defined the design of remote sensing instruments and the derivation of various metrics for vegetation monitoring. The AVHRR's wide spectral bandwidths are subject to atmospheric interference (specifically aerosols and water vapor). 
of the vegetation, and hence NIR reflectance is directly related to the green leaf density (Gates et al., 1965; Knipling, 1970; Woolley, 1971). These characteristics drive the spectral response of plants in these two spectral regions, and the reflectances vary with seasonal changes in vegetation condition (phenology) and/or stress (e.g., drought). When captured remotely through time, such variations can be exploited for vegetation drought-monitoring purposes. The ratio between red and NIR reflectances was named the Vegetation Index (VI). There were other variants of the VI such as the Transformed Vegetation Index (square-root transformation of difference-sum ratio), the Simple Ratio (red/infrared), and the Perpendicular Vegetation Index (Rouse et al., 1974a,b; Deering et al., 1975; Richardson and Weigand, 1977). Eventually, researchers agreed upon the Normalized Difference Vegetation Index (NDVI) as the most efficient and simple metric to identify vegetated areas and their condition (Tucker, 1979). Normalization had many advantages, including minimizing directional reflectance and off-nadir viewing effects; reducing sun-angle, shadow, and topographic variation effects; and minimizing aerosol and water-vapor effects (Holben, 1986). This normalization enabled large-scale vegetation monitoring, allowing comparison of different regions through time.

The NDVI is computed as follows:

$$
\mathrm{NDVI}=\frac{\mathrm{NIR}-\mathrm{RED}}{\mathrm{NIR}+\mathrm{RED}}
$$

where RED and NIR are the spectral reflectance measurements in the red and NIR regions of the electromagnetic spectrum, respectively. These spectral reflectances are ratios of reflected radiation to incoming radiation in each spectral band, with values ranging between 0.0 and 1.0. Theoretically, NDVI values can range between -1.0 and +1.0 . However, the typical range of NDVI measured from vegetation and other earth surface materials is between about -0.1 (NIR less than RED) for nonvegetated surfaces and as high as 0.9 for dense green vegetation canopies (Tucker, 1979). The NDVI increases with increasing green biomass, changes seasonally, and responds to favorable (e.g., abundant precipitation) or unfavorable climatic conditions (e.g., drought). This early research was based on the ERTS program of the National Aeronautics and Space Administration (NASA), now known as the Landsat program. However, because of the low repeat cycle of the satellite (18 days) and persistent cloud cover, ERTS could not by itself provide the temporal frequency of measurements for systematic monitoring of the land surface for drought and other environmental applications that need cloudfree measurements.

\subsection{BRIEF HISTORY OF AVHRR}

From 1980 to 1982, independent teams of researchers with an interest in landsurface monitoring demonstrated that the visible channels on the NOAA AVHRR could be exploited for vegetation monitoring (Tucker et al., 1983). For the first time, vegetation could be monitored at a global scale from a satellite platform with a high temporal frequency of repeat observations (near-daily global coverage). This meant 
that aspects of vegetation seasonality and health could be studied and monitored over time. However, measurements for land-surface monitoring were not originally planned in the instrumental design of the NOAA polar-orbiting satellite program. The first-ever AVHRR was flown on the TIROS-N meteorological satellite in 1978. This AVHRR was configured with four spectral channels (0.55-0.90, 0.73-1.1, 3.5-3.9, and $10.5-11.5 \mu \mathrm{m}$ ) customized for meteorological observations and applications. Table 2.1 shows the spectral bandwidths of various AVHRR platforms and their possible uses and applications. Note that some channel bandwidths have changed over time with observational and technological requirements.

After this pioneer mission, it became apparent that future AVHRR sensors required modifications to increase effectiveness for snow mapping and vegetation monitoring, primarily by narrowing the first channel in the red spectral region to $0.55-0.68 \mu \mathrm{m}$ (Schneider et al., 1981). Since chlorophyll absorption of solar radiation is confined to these wavelengths, narrowing the first channel made detecting and mapping vegetation

\section{TABLE 2.1}

\section{AVHRR Spectral Channels, Resolution, and Primary Uses}

\begin{tabular}{|c|c|c|c|c|c|}
\hline $\begin{array}{l}\text { Channel } \\
\text { Number }\end{array}$ & $\begin{array}{l}\text { Wavelength } \\
(\mu \mathrm{m}) \\
\text { TIROS-N }\end{array}$ & $\begin{array}{c}\text { Wavelength }(\mu \mathrm{m}) \\
\text { NOAA-6, } \\
8,10,12,14,16,18\end{array}$ & $\begin{array}{c}\text { Wavelength }(\mu \mathrm{m}) \\
\text { NOAA-7, } \\
9,11,15,17\end{array}$ & $\begin{array}{l}\text { IFOV } \\
\text { (mrad) }\end{array}$ & Primary Uses \\
\hline 1 & $0.550-0.90$ & $0.580-0.68$ & $0.58-0.68$ & 1.39 & $\begin{array}{l}\text { Daytime cloud/ } \\
\text { surface and } \\
\text { vegetation mapping }\end{array}$ \\
\hline 2 & $0.725-1.10$ & $0.725-1.10$ & $0.725-1.0$ & 1.41 & $\begin{array}{l}\text { Surface water, ice, } \\
\text { snow melt, and } \\
\text { vegetation mapping }\end{array}$ \\
\hline $3 \mathrm{~A}$ & & $1.58-1.64^{(\mathrm{NOAA}-16,18)}$ & $1.58-1.64$ (NOAA-15,17) & 1.3 & $\begin{array}{c}\text { Snow and ice } \\
\text { detection }\end{array}$ \\
\hline $3 \mathrm{~B}$ & $3.550-3.93$ & $3.550-3.93$ & $3.55-3.93$ & 1.51 & $\begin{array}{l}\text { Sea surface } \\
\text { temperature, } \\
\text { nighttime cloud } \\
\text { mapping }\end{array}$ \\
\hline 4 & $10.500-11.50$ & $10.500-11.50$ & $10.3-11.3$ & 1.41 & $\begin{array}{l}\text { Sea surface } \\
\text { temperature, day } \\
\text { and night cloud } \\
\text { mapping }\end{array}$ \\
\hline 5 & Ch4 repeated & Ch4 repeated & $11.5-12.5$ & 1.30 & $\begin{array}{l}\text { Sea surface } \\
\text { temperature, day } \\
\text { and night cloud } \\
\text { mapping }\end{array}$ \\
\hline
\end{tabular}

Source: Compiled from NOAA Satellite and Information Services, NOAA Polar Orbiter Data User's Guide, Silver Spring, MD, http://psbcw1.nesdis.noaa.gov/terascan/home_basic/polarsats_ sensors_tables.html (accessed December 12, 2011).

Note: The instantaneous field of view (IFOV) of each channel is approximately $1.4 \mathrm{mrad}$, leading to a resolution at the satellite subpoint of $1.1 \mathrm{~km}$ for a nominal altitude of $850 \mathrm{~km}$ (528 miles). 
more effective, as opposed to the wider channel on the first TIROS, which constrained vegetation monitoring because of atmospheric attenuation. After the launch of the NOAA-6 platform in 1979, a new unintended measurement became possible from meteorological satellites: the NDVI. A major advantage of AVHRR is its daily global coverage. Because of the instrument's wide field of view $\left( \pm 55^{\circ}\right)$ and polar-orbiting, sunsynchronous orbit, the AVHRR images the earth's land surface twice daily (day and night). Data collected over consecutive days minimize the effects of cloud cover and other unfavorable atmospheric conditions. The high temporal resolution of AVHRR, coupled with continual operational data acquisitions over many years, provides a historical context for long-term monitoring and comparison of land-surface conditions. Metrics obtained through image differencing or other decomposition techniques can be used to identify different types of ecosystem anomalies that can be used for drought detection (Tucker et al., 1986, 1991; Eastman and Fulk, 1993; Tucker, 1996). At present, a 30 year history of global AVHRR NDVI measurements (Table 2.2) sets a climate-scale benchmark for land-surface studies and applications (Figure 2.2). This long-term data set can be used to study aspects of drought frequency and extent, as well as relationships between drought and climate variability.

\subsection{NORMALIZED DIFFERENCE VEGETATION INDEX}

\subsubsection{NDVI Derived from AVHRR MeAsurements}

The NDVI from broadband AVHRR data is calculated from channels $1(0.55-0.70 \mu \mathrm{m})$ and $2(0.73-1.1 \mu \mathrm{m})$ using the following equation:

$$
\text { NDVI }=\frac{\text { Channel } 2-\text { Channel } 1}{\text { Channel } 2+\text { Channel } 1}
$$

Figure 2.1 shows a comparison between AVHRR and Landsat TM spectral bandwidths for vegetation mapping and their respective spectral responses. Often, AVHRR's channel 4 or $5(10.3-11.3,11.5-12.5 \mu \mathrm{m})$ is used as a thermal cloud mask. The thermal cloud mask eliminates NDVI data below a set brightness temperature threshold, which is usually around $285 \mathrm{~K}$. In most tropical latitudes, it is assumed that the surface brightness temperatures will be above the threshold value (even at high elevations during the afternoon AVHRR overpasses). Since cloud pixels typically have brightness temperatures less than the land surface, the corresponding NDVI pixels are masked (Holben, 1986). Kimes (1983) and Holben and Fraser (1984) found that several factors unrelated to vegetation condition can affect NDVI over green vegetation, including atmospheric effects, cloud detection, and bidirectional reflectance effects. Different compositing techniques had to be investigated to form solutions to these issues (Kimes, 1983; Gatlin et al., 1984; Holben and Fraser, 1984; Kimes et al., 1984; Holben, 1986; Holben et al., 1986). One such technique was to form time-composite images of maximum NDVI values over periods of several days, such as 7-day, 10-day, 15-day, or monthly intervals (Holben and Fraser, 1984; Holben, 1986). The use of a thermal cloud mask combined with maximum value compositing (MVC) reduces the effects of cloud contamination, atmospheric 
TABLE 2.2

NOAA POES Launch Dates and Periods of Operation

\begin{tabular}{|c|c|c|c|c|}
\hline $\begin{array}{l}\text { Name after } \\
\text { Launch }\end{array}$ & $\begin{array}{l}\text { Name before } \\
\text { Launch }\end{array}$ & Date of Launch & AVHRR Version & $\begin{array}{l}\text { Spacecraft Mission } \\
\text { Operational Status }\end{array}$ \\
\hline TIROS-N & TIROS-N & October 1978 & & $?$ \\
\hline NOAA-6 & NOAA-A & June 27, 1979 & & $\begin{array}{l}\text { End of mission: November } \\
11,1986\end{array}$ \\
\hline NOAA-7 & NOAA-C & June 23, 1981 & 2 & End of mission: June 7, 1986 \\
\hline NOAA-8 & NOAA-E & March 28, 1983 & 1 & $\begin{array}{l}\text { End of mission: October 31, } \\
1985\end{array}$ \\
\hline NOAA-9 & NOAA-F & $\begin{array}{l}\text { December 12, } \\
1984\end{array}$ & 2 & $\begin{array}{l}\text { End of mission: November 5, } \\
1994\end{array}$ \\
\hline NOAA-10 & NOAA-G & $\begin{array}{l}\text { September } 17 \text {, } \\
1986\end{array}$ & 1 & $\begin{array}{l}\text { Decommissioned: September } \\
17,1991\end{array}$ \\
\hline NOAA-11 & NOAA-H & $\begin{array}{l}\text { September 24, } \\
1988\end{array}$ & 2 & $\begin{array}{l}\text { Decommissioned: June 16, } \\
2004\end{array}$ \\
\hline NOAA-12 & NOAA-D & May 15, 1991 & 1 & $\begin{array}{l}\text { Decommissioned: August } 10 \text {, } \\
\text { 2007, after setting an } \\
\text { extended lifetime record of } \\
\text { over } 16 \text { years }\end{array}$ \\
\hline NOAA-13 & NOAA-I & August 1993 & & $\begin{array}{l}\text { Failure after launch: } 2 \text { weeks } \\
\text { after launch, the spacecraft } \\
\text { suffered a catastrophic } \\
\text { power system anomaly }\end{array}$ \\
\hline NOAA-14 & NOAA-J & $\begin{array}{l}\text { December 30, } \\
1994\end{array}$ & 2 & $\begin{array}{l}\text { Decommissioned: May 23, } \\
2007\end{array}$ \\
\hline NOAA-15 & NOAA-K & May 13, 1998 & 3 & AM secondary \\
\hline NOAA-16 & NOAA-L & $\begin{array}{l}\text { September 21, } \\
2000\end{array}$ & 3 & PM secondary \\
\hline NOAA-17 & NOAA-M & June 2002 & 3 & AM backup \\
\hline NOAA-18 & NOAA-N & May 20, 2005 & 3 & PM secondary \\
\hline NOAA-19 & NOAA-O & $\begin{array}{l}\text { February 6, } \\
2009\end{array}$ & 3 & PM primary \\
\hline METOP-A & & $\begin{array}{l}\text { October } 19, \\
2006\end{array}$ & 3 & AM primary \\
\hline
\end{tabular}

Source: Compiled from NOAA Satellite and Information Service, Silver Spring, MD, http://www.oso. noaa.gov/history/first-launched.htm (accessed on December 12, 2011).

Note: The AVHRR instrument is a cross-track scanning system similar to the former VHRR on TIROS-N but features four (AVHRR/1), five (AVHRR/2), or six (AVHRR/3) spectral channels. Note that METOP mission is owned and operated by EUMETSAT to provide data for the AM orbit. 

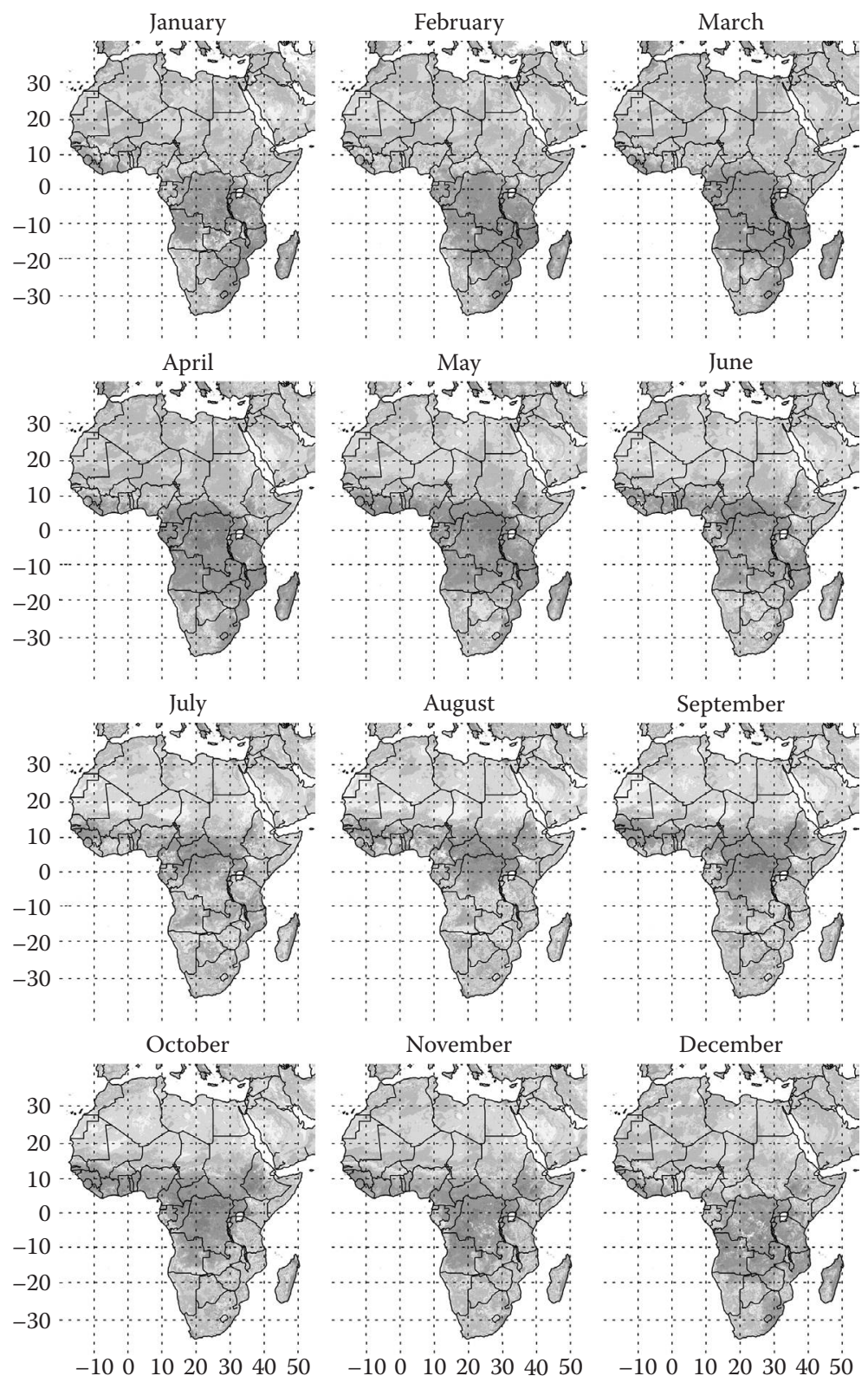

December

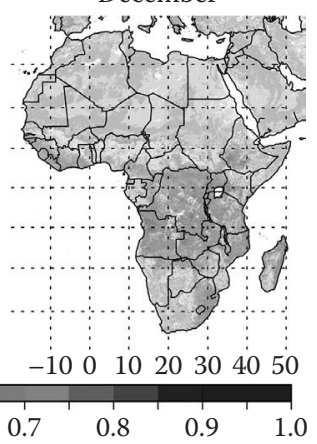

FIGURE 2.2 (See color insert.) Example of typical monthly NDVI time-series data for Africa and the Middle East. In general, areas of high NDVI or high vegetation density are represented in shades of green while areas of low NDVI/low vegetation density such as semiarid lands and Sahara and Arabian deserts are shown in shades of yellow to brown. The patterns change seasonally from January through December. (Data produced by GIMMS Group at NASA/GSFC, Greenbelt, MD.) 
attenuation, view and illumination geometry, and surface directional reflectance. This is because maximum NDVI values are found to be associated with a clear atmosphere, while compositing tends to minimize other angular effects.

MVC was enacted as standard operating procedure in 1983 for the production of global AVHRR products generated by the Global Inventory Monitoring and Modeling Studies (GIMMS) group at the NASA Goddard Space Flight Center (GSFC). Reasons for enacting this as standard protocol were (a) the AVHRR channels 1 and 2 are spectrally very wide, (b) channel 2 contains a water absorption band, (c) directional effects were not well understood for broadband sensors, and (d) detailed atmospheric data were not available for explicit atmospheric correction. Therefore, since atmospheric conditions tend to suppress NDVI values in a nonclear atmosphere, MVC was the preferred solution.

\subsubsection{INTERPRETATION OF NDVI}

Radiation measurements of the earth's surface from satellites are complex functions of not only the state and properties of the surface itself but also the conditions and dynamics of the atmosphere through which the reflected radiation is sensed. NDVI and other derived VIs are an attempt to provide the best estimates of the state and condition of vegetation while minimizing (or eliminating) the influence of other factors, as mentioned in the previous section. Derived metrics have to be universal and reliable in time and space, irrespective of these extraneous factors. A detailed analysis of the interpretation of VIs is given by Myneni et al. (1995), who concluded that NDVI represents the energy that drives photosynthesis. Over the past two decades, the NDVI has been widely used in many terrestrial applications. Some examples include drought early warning, locust monitoring, vector disease risk assessment, estimation of forage, agricultural monitoring, land cover classification, and as an input to land-surface and biophysical models. Early proof-of-concept studies showed NDVI to be a nondestructive measure of intercepted photosynthetically active radiation (PAR) (Asrar et al., 1984, 1985; Hatfield et al., 1984; Wiegand and Richardson, 1984), photosynthetic capacity, and primary production (Kumar and Monteith, 1982; Sellers, 1985, 1987; Asrar et al., 1986; Tucker and Sellers, 1986). Other studies used NDVI to study total biomass production for a wide range of vegetation types, including grasslands, agricultural crops, and salt marshes (Steven et al., 1983; Tucker et al., 1983, 1985b; Hardisky et al., 1984). Intensive field studies using a combination of time-series AVHRR NDVI data and ground-based spectral measurements were used to estimate total biomass production in savanna ecosystems (Tucker et al., 1983, 1985b; Hiernaux and Justice, 1986; Prince and Tucker, 1986). Results from these studies showed that the cumulative NDVI was linearly related with the total aboveground dry biomass sampled at the end of the growing season over the Sahelian zone of Africa, as shown in Figure 2.3.

\subsubsection{Early Applications of NDVI}

Researchers began to build on these early findings with large-scale studies using coarse-resolution AVHRR NDVI data to map regional-to-continental scale vegetation types (Norwine and Greegor, 1983; Justice et al., 1985; Townshend et al., 1985, 


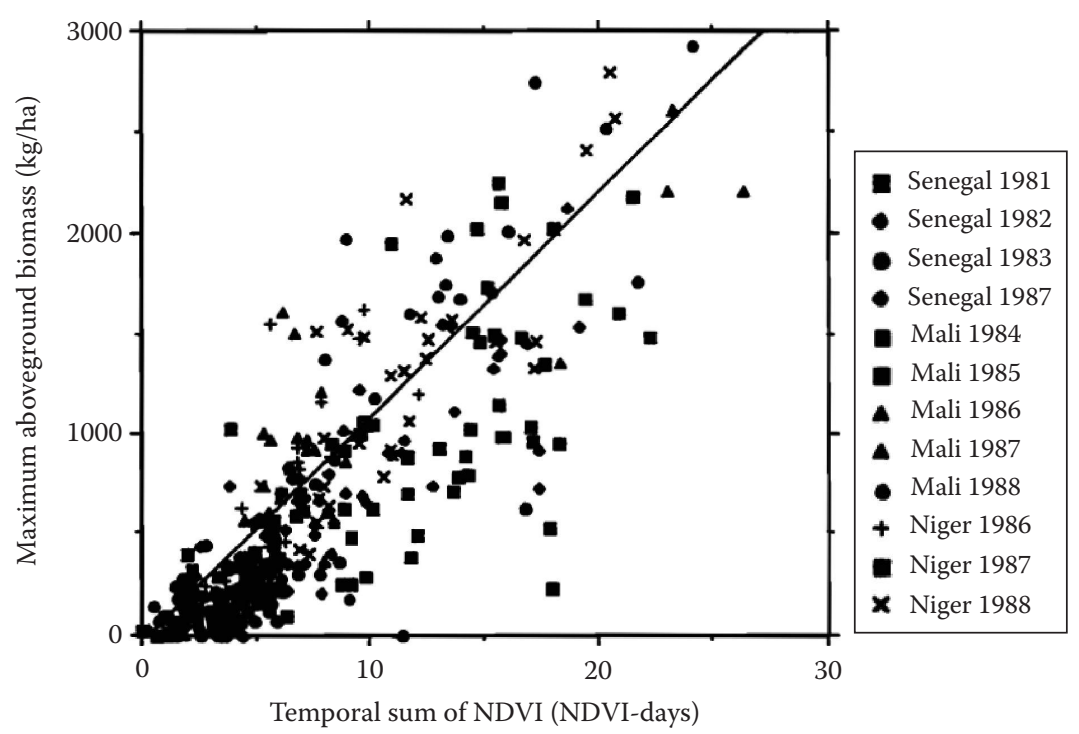

FIGURE 2.3 Summary figure for the NOAA AVHRR $1 \mathrm{~km}$ NDVI-Sahelian biomass relationship from 1981 to 1988 . The figure presents a comparison between ground measurements of aboveground total dry herbaceous biomass sampled at the end of the growing season and time-integrated NDVI data for each country/year combination. (From Prince, 1991: [biomass $(\mathrm{kg} / \mathrm{ha})=-86+114 *$ NDVI-days; Confidence Intervals: @3 NDVI-days, $\pm 61 \mathrm{~kg} / \mathrm{ha}$; @10 NDVI-days, $\pm 51 \mathrm{~kg} / \mathrm{ha}$.]) (Adapted from Tucker, C.J., History of the use of AVHRR data for land applications, in Advances in the Use of NOAA AVHRR Data for Land Applications, Kluwer Academic Publishers, Dordrecht, the Netherlands, 1996, pp. 1-19.)

1987; Tucker et al., 1985a; Dyer and Crossley 1986; Loveland et al., 1991; Tateishi and Kajiwara, 1992; Eastman and Fulk, 1993; Stone et al., 1994). These studies assumed that mapping the photosynthetic capacity of vegetation would lead to disaggregation of the land surface into land cover groupings based on vegetation function. Pertinent examples of such successful studies were (1) land cover mapping, (2) investigating the relationship between photosynthetic capacity and rainfall in semiarid lands (Figure 2.4) (Nicholson et al., 1990; Tucker et al., 1991), and (3) monitoring ecological conditions favorable for insects and birds in arid and semiarid ecosystems (Tucker et al., 1985c; Hielkema et al., 1986). These studies led to the first use of AVHRR NDVI data in drought and desert locust monitoring through cooperation among NASA GSFC, the Food and Agricultural Organization (FAO), and the U.S. Agency for International Development (USAID) (Hutchinson, 1991; Tucker, 1996).

\subsection{AVHRR NDVI DROUGHT APPLICATIONS}

The absence of reliable, continuous, and high-density time series of terrestrial weather and climate observations for most parts of the world made it difficult to monitor the spatial patterns of drought and other climate-related anomalies in the past (Janowiak, 1988; Nicholson, 1989). The 1983-1985 large-scale drought that affected 


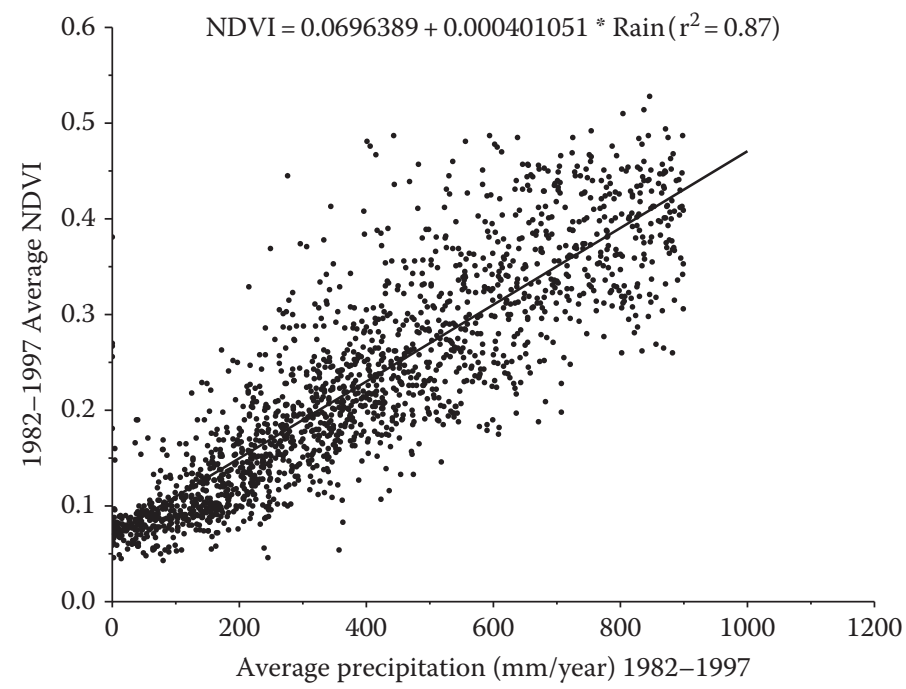

FIGURE 2.4 Comparison between average precipitation from 1982 to 1987 for 1794 stations from West Africa and coincident NDVI. (Data updated and adapted from Tucker, C.J., History of the use of AVHRR data for land applications, in Advances in the Use of NOAA AVHRR Data for Land Applications, Kluwer Academic Publishers, Dordrecht, the Netherlands, 1996, pp. 1-19.)

the Sahel region of Africa was the signature event that eventually led to the use of coarse spatial resolution AVHRR NDVI data for drought monitoring (Figure 2.5).

High temporal resolution data are a key factor for drought monitoring in order to capture the frequency of rainfall events (Tucker et al., 1986). During the early 1980s drought, most rainfall data records that were available through

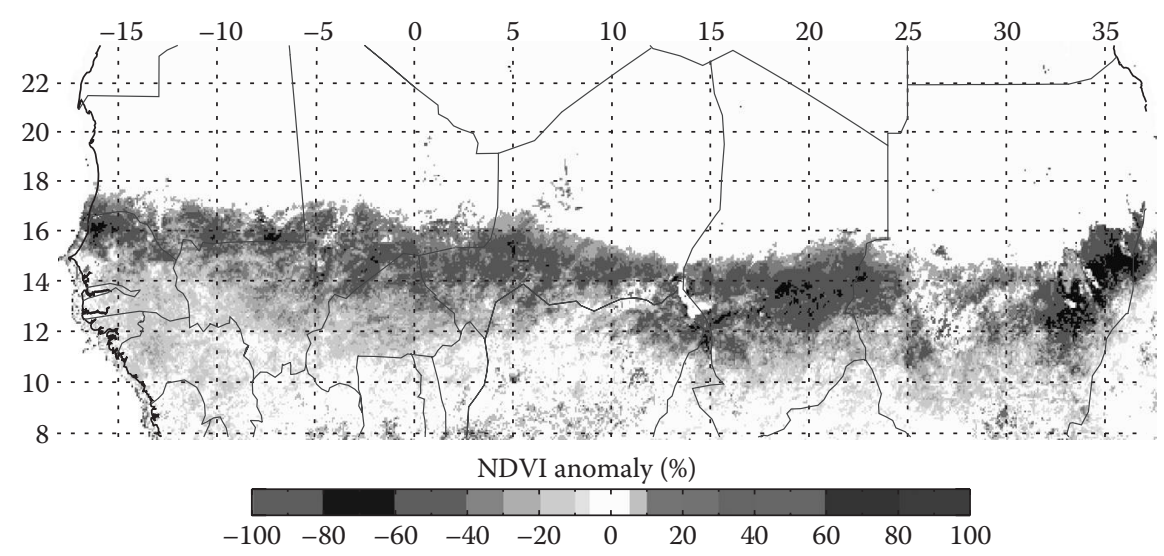

FIGURE 2.5 (See color insert.) Growing season (July-October) NDVI anomaly for the Sahel region showing the large areal extent of the Sahelian drought in 1984. Before AVHRR NDVI data became available, such regional-to-continental mapping of drought extent and patterns was not possible. (Adapted from Anyamba, A. and Tucker, C.J., J. Arid Environ., 63, 596, 2005.) 
the World Meteorological Organization (WMO) and national meteorological services were compiled as weekly or 10 day cumulative records. Comparisons with near-real-time rainfall data could be made by temporally sampling the AVHRR NDVI data to form weekly and decadal composites for drought monitoring, particularly with regard to agricultural conditions. Tucker et al. (1991) demonstrated that intercomparisons of extended time series of NDVI data can provide useful information for drought monitoring in the Sahel region. Baseline vegetation conditions for the growing season (i.e., July-October) were defined as the mean NDVI calculated over several years, and the coefficient of variation in NDVI was used to represent variation between growing seasons. Drought and areas of high interannual vegetation variability were reflected in the multitemporal AVHRR NDVI data sets, especially in the Sahel between the 1984-1985 drought years and the wet year in 1988 (Tucker et al., 1991). With a baseline established for vegetation (by month or growing season), current conditions could be assessed as above, below, or near normal, which is particularly important for monitoring agricultural conditions and determining agricultural production estimates. This was a pioneering first step toward using interannual and/or anomaly analysis of NDVI for drought monitoring of vegetation. Other related efforts have applied NDVI for drought monitoring (Gallo, 1990; Kogan, 1990, 1995a; Eidenshink and Hass, 1992; Burgan and Hartford, 1993; Burgan et al., 1996; Unganai and Kogan, 1998, among many others). Several NDVI-based indices developed for monitoring drought are discussed in the following section, including vegetation condition conveyed by remotely sensed land-surface temperature (LST).

\subsubsection{Drought Monitoring Using NDVI}

\subsubsection{NDVI Anomalies}

The simplest and most common NDVI-based methods of detecting and mapping drought use NDVI anomalies. Anomalies are calculated as the difference between the NDVI composite value for a specified time period (e.g., week, biweek, or month) and the long-term mean value for that period. This isolates the variability in the vegetation signal and establishes a meaningful historical context for the current NDVI to determine relative drought severity. Anyamba and Tucker (2005) found that negative NDVI anomalies could identify and map the spatial extent of drought response in vegetation with a baseline period of 20 years for the Sahel region (Figure 2.5). Other related studies have demonstrated strong relationships on an interannual time scale between NDVI anomalies and El Niño/La NiñaSouthern Oscillation (ENSO) phenomena for east Africa (Anyamba and Eastman, 1996; Anyamba et al., 2001), southern Africa (Verdin et al., 1999; Martiny et al., 2006), the southeastern United States (Mennis, 2001), Brazil (Liu and Negron Juarez, 2001; Barbosa et al., 2006), the northern hemisphere (Lotsch et al., 2005), and globally (Myneni et al., 1996; Los et al., 2001). By understanding the relationship between ENSO events and drought occurrence, the dynamics of NDVI anomalies can be used to predict an oncoming drought (Liu and Negron Juarez, 2001). 


\subsubsection{Standardized Vegetation Index}

Building on the NDVI anomaly concept, the Standardized Vegetation Index (SVI) developed by Peters et al. (2002) describes the probability of variation from normal NDVI over multiple years of data (e.g., 12 years), on a weekly time step. The SVI is calculated as a $Z$-score deviation from the mean in units of the standard deviation, calculated from the NDVI values for each pixel location of a composite period for each year during a given reference period. This is expressed in equation form as follows:

$$
Z_{i j k}=\frac{\operatorname{NDVI}_{i j k}-\overline{\mathrm{NDVI}}_{i j}}{\sigma_{i j}}
$$

where

$Z_{i j k}$ is the $Z$-score for year $k$

$\mathrm{NDVI}_{i j k}$ is the weekly NDVI value

$\mathrm{NDVI}_{i j}$ is the mean NDVI value

$\sigma_{i j}$ is the standard deviation in NDVI for pixel $i$ during week $j$

The SVI was found to provide useful drought-related vegetation condition information over the U.S. Great Plains in near real time (Peters et al., 2002). Due to the weekly time step of the SVI maps, this method can capture the rapidly changing patterns of drought and its severity during the growing season over a large area.

\subsubsection{Drought Monitoring Using NDVI and Land-Surface Temperature}

\subsubsection{Vegetation Condition Index}

Kogan and Sullivan (1993) introduced a vegetation index-based drought metric called the Vegetation Condition Index (VCI) and developed a global drought-watch system using this index derived from AVHRR smoothed weekly NDVI data. The VCI is defined as follows:

$$
\mathrm{VCI}=\frac{\left(\mathrm{NDVI}-\mathrm{NDVI}_{\min }\right) \times 100}{\mathrm{NDVI}_{\max }-\mathrm{NDVI}_{\min }}
$$

where NDVI, NDVI ${ }_{\text {max }}$, and $\mathrm{NDVI}_{\text {min }}$ are values of the smoothed weekly NDVI and the multiple-year NDVI maximum and minimum, respectively. The smoothed weekly data are scaled relative to the amplitude of their range at each given pixel location and then linearly scaled with a minimum of 0 and maximum of 100 . Low values of VCI indicate poor/stressed vegetation due to unfavorable weather conditions, and high values of VCI indicate healthy vegetation conditions. The pixel-based normalization is performed to minimize the effect of spurious or short-term signals in the data and to amplify the long-term ecological signal. In a VCI study conducted by Liu and Kogan (1996), both NDVI anomalies and the VCI were shown 
to be correlated with rainfall anomalies. However, VCI was found to be more useful for seasonal and interannual comparisons of drought conditions over the South American continent. A study in India found that the utility of the VCI for drought monitoring was improved when used in conjunction with the Temperature Condition Index (TCI) (Singh et al., 2003), which is calculated from AVHRR's thermal channels $(10.3-11.3 \mu \mathrm{m})$. The TCI is defined as follows:

$$
\mathrm{TCI}=\frac{100\left(\mathrm{BT}_{\max }-\mathrm{BT}\right)}{\mathrm{BT}_{\max }-\mathrm{BT}_{\min }}
$$

where $\mathrm{BT}, \mathrm{BT}_{\max }$, and $\mathrm{BT}_{\min }$ are the smoothed weekly and multiple-year maximum and minimum thermal brightness temperatures, respectively. Liu and Kogan (1996) found that the TCI performed better than NDVI and VCI, especially in cases where soil moisture is excessive because of heavy rainfall or persistent cloudiness. Under such conditions, NDVI is depressed, and VCI values are low, which can be interpreted erroneously as drought. To address the issue of false positives for drought, a third VCI (VHI, Vegetation Health Index) was developed by Kogan (1995a), combining the VCI and TCI. VHI is expressed mathematically as follows:

$$
\mathrm{VHI}=\alpha \times \mathrm{VCI}+(1-\alpha) \times \mathrm{TCI}
$$

where $\alpha$ is a coefficient determining the relative contribution of the TCI and VCI. Thus, VHI is a proxy characterizing vegetation health by combining estimation of moisture and thermal conditions. Global maps of VCI, TCI, and VHI are routinely produced and distributed by NOAA-NESDIS at http://www.star.nesdis.noaa.gov/ smcd/emb/vci/VH/vh_ftp.php.

\subsubsection{Temperature-NDVI Ratio Index}

Another drought index called the temperature-NDVI ratio was made by integrating LST and NDVI data. In a study to assess drought impacts over Papua New Guinea, McVicar and Bierwirth (2001) developed this drought index as a ratio of LST and NDVI, which they defined as $T_{\mathrm{s}} /$ NDVI. During a large-scale drought in 2007, the integral of this ratio over the period from January to December showed a strong positive correlation $\left(r^{2}=0.82\right)$ with severe drought conditions in most of the provinces experiencing food shortages. Additionally, the index had an inverse relationship $\left(r^{2}=0.81\right)$ when plotted against cumulative rainfall from various meteorological stations in areas experiencing drought. The results from the study demonstrated that the composite AVHRR $T_{\mathrm{s}} / \mathrm{NDVI}$ ratio provides an effective and rapid way to assess drought conditions. Under conditions of vegetation stress, $T_{\mathrm{s}}$ increases because of lower transpiration rates and decreases at high NDVI values because of higher transpiration rates associated with increased photosynthetic activity.

\subsubsection{Limitations of NDVI as a Drought-Monitoring Tool}

The studies previously described illustrate the wide range of applications of NDVI and NDVI-thermal-based indices for drought monitoring. They also bring to light 
some possible limitations and shortcomings of using NDVI, NDVI-derived indices, and combined NDVI-thermal indices for drought applications. Of particular relevance are the limitations of NDVI over dense vegetation canopy areas. For example, in areas such as tropical forests and the boreal regions of the northern hemisphere, NDVI saturates, and the relationship between NDVI and canopy dynamics will break down. In very wet ecosystems, where soil moisture does not limit vegetation growth, the relationship does not hold at the peak of the growing season when NDVI reaches its maxima, although rainfall may still be increasing (Nicholson et al., 1990; Baret and Guyot, 1991; Wang et al., 2005). In such areas, the seasonal variation of NDVI is too small to discern significant drought events. Furthermore, many of these areas have persistent cloud cover throughout the year (Holben, 1986; Fensholt et al., 2006b,c), which can lead to biases in anomaly analysis; this is because of the limited cloud-free observations available to calculate the NDVI and LST long-term means.

In semiarid areas with sparse vegetation canopies, soil background conditions exert considerable influence on partial canopy spectra and the calculated VIs. Such soil background conditions include primary variations associated with the brightness of bare soil and secondary variations associated with "color" differences among bare soils, as well as soil-vegetation spectral mixing. For example, a brighter soil background results in higher NDVI values than a dark soil background for the same quantity of partial vegetation cover (Huete et al., 1985; Huete, 1988; Huete and Tucker, 1991). In a study over the Sahel, secondary soil variance was responsible for the Saharan desert "artifact" areas of increased VI response in AVHRR NDVI imagery. Some bare soil areas on the margins of deserts result in high NIR reflectance relative to the red reflectance, which artificially enhances the system NDVI. On the other hand, in the Negev Desert, high NDVI values are shown to be associated with photosynthetic activity of microphytes (lower plants, consisting of mosses, lichens, algae, and cyanobacteria), which cover most of the rock and soil surfaces in this semiarid region (Karnieli et al., 1996). Therefore, both soil characteristics and reflectance of lower plant communities may lead to misinterpretation of the vegetation dynamics and overestimation of ecosystem productivity and drought conditions in some semiarid environments.

Indices that incorporate NDVI and LST, such as VHI and the Vegetation Temperature Condition Index (VTCI), rely on a strong inverse relationship between NDVI and LST. Increasing LST is assumed to negatively impact vegetation vigor and consequently cause plant stress. However, this hypothesis does not hold across all global ecosystems. For example, in northern hemisphere and high-altitude ecosystems (like Mongolia), where temperature is a limiting factor on vegetation growth, a positive correlation is found between these two variables. Therefore, neither of the two indices can truly indicate drought in such places (Karnieli et al., 2006, 2010). In these ecosystems, warmer temperatures usually mean more favorable rather than adverse growing conditions for vegetation. Furthermore, even in areas where this NDVI-LST relationship is assumed to be predominantly positive, it has been shown that the relationship varies with location, season, and vegetation type (Lambin and Ehrlich, 1996; Tateishi and Ebata, 2004). Therefore, the application of empirical NDVI-LST-based indices such as VHI and VTCI must be restricted to areas and periods where negative correlations are observed and not on a global scale (Karnieli et al., 2010). 


\subsection{OPERATIONAL NDVI-BASED DROUGHT-MONITORING SYSTEMS}

Ecosystems such as the grasslands of East Africa, the Sahel, and North America are excellent examples of where NDVI can be effectively used to monitor vegetation and drought conditions. This is because the phenology of vegetation closely reflects the seasonal cycle of rainfall (Justice et al., 1985; Nicholson et al., 1990; Ji and Peters, 2004). Using this knowledge, a drought-monitoring product was prototyped for the central United States using AVHRR NDVI data as a primary input (Brown et al., 2002, 2008) with the purpose of providing vegetation-specific drought information. This product, known as the Vegetation Drought Response Index (VegDRI), has since been expanded to cover the rest of the continental United States (Wardlow et al., 2009). VegDRI integrates satellite-based observations of vegetation (AVHRR NDVI) with climatebased drought indices, as well as other biophysical information (such as land use/land cover type, soil characteristics, elevation, and ecological conditions). With these data, drought severity maps are produced to indicate any drought-related vegetation stress.

Another drought-monitoring risk-based system was developed for East and Southeast Asia. The system analyzes current vegetation conditions (inferred from AVHRR NDVI) and precipitation data by comparing 10-day intervals to long-term means, in an effort to detect areas of drought and its effects on agriculture (Song et al., 2004). This and many other national early warning and drought-monitoring systems (e.g., VegDRI) are based largely upon the pioneering efforts of the USAID to establish the Famine Early Warning System Network (FEWS NET) in 1985. FEWS NET brought together the U.S. government agencies NASA, U.S. Geological Survey (USGS), and NOAA to provide technical expertise, data (including NDVI), and data systems integration for drought monitoring over sub-Saharan Africa. This system has now grown to include Haiti, Central America, and Afghanistan. At the global level, FAO created the Global Information and Early Warning System on Food and Agriculture (GIEWS). GIEWS relies on FAO's Africa Real-Time Environmental Monitoring Information System (ARTEMIS), which has been in existence since 1988. ARTEMIS provides analysis of near-real-time AVHRR NDVI data and European Meteosat satellite cold cloud duration (CCD) images (as a proxy for rainfall) over Africa every 10 days. With a historical satellite record since 1988, GIEWS analysts can pinpoint areas experiencing anomalously low rainfall. Around the world, several national and regional-level drought-monitoring centers use NDVI data from AVHRR or other satellite systems as major input to their drought-monitoring activities. Two such examples are the AVHRR NDVI-based greenness products produced operationally for the continental United States by the USGS Earth Resources Observation and Science (EROS) Center (http://ivm.cr.usgs.gov/) and Australia's AVHRR NDVIbased drought-monitoring system (http://www.bom.gov.au/sat/NDVI/NDVI2.shtml).

\subsection{RECENT DEVELOPMENTS IN NDVI ANALYSES}

In earlier studies, a major impediment to using AVHRR NDVI in environmental and drought monitoring was the lack of a long-term time series of measurements to establish historically meaningful baselines. By the early 1990s, a sufficiently long 
time series ( 20 years) of NDVI observations had been collected for research to start utilizing the data set for large-scale drought monitoring and studying the relationship between vegetation and large-scale climate variability. Such long-term analysis studies have employed time-series decomposition techniques such as principal component analysis (PCA) (Eastman and Fulk, 1993), which decompose the NDVI image time series into various spatial and temporal components (Figure 2.6). In general, the first four principal components explain most of the variance in the data set and characterize long-term conditions and different seasonality regimes. Lower-order components were primarily related to interannual climate events (such as ENSO), localized patterns, and nonvegetation-related noise from changes in different satellite platforms over time (Anyamba and Eastman, 1996). Fourier analysis is another decomposition technique that can detect temporal variability patterns by breaking NDVI into phase and amplitude components (Azzali and Menenti, 2000). However, Fourier analyses require stationary data, whereby statistical parameters describing the data series (such as the mean and variance) do not change over space or time. AVHRR NDVI data series, in particular, do not have these characteristics because NDVI is subject to external factors like weather, climate, and human influences (land cover transformation), which change the nature of its statistics over time. Therefore, applying a Fourier transform to nonstationary NDVI time series results in spurious signals. Such signals are not related to ecosystem dynamics because the technique assumes harmonic behavior; the results are time-dependent periodic signals, each defined by a unique phase and amplitude value. Although regular events such as the seasonality of vegetation can be extracted, interannual patterns (and hence long-term trends) like drought are not easily resolved. As a result, the use of Fourier analyses on nonstationary NDVI data should be performed with caution, with a focus on extracting patterns of seasonality.

Another technique is anomaly analysis, where departures from a base mean period are used to detect periodic temporal patterns in NDVI. These types of analyses have been used to evaluate the relationships between NDVI anomaly patterns and ENSO in different regions of the world (Anyamba and Eastman 1996; Myneni et al., 1996; Anyamba et al., 2002), linking vegetation response to variations in large-scale climate mechanisms (see Figure 2.6 as an example). The understanding of such linkages or teleconnection patterns, especially the driving mechanisms, can be used in predicting areas that are likely to be impacted by drought (Verdin et al., 1999; Funk et al., 2008).

Unlike floods, drought is a creeping phenomenon, and some studies are now attempting to use time-integrated NDVI data to represent the cumulative aspect of drought. As shown in the example for Australia in Figure 2.7, the impacts of drought (A and B) can be detected as increasing cumulative severity (negative NDVI anomalies) through the 2006-2007 growing season. This drought pattern is a sharp contrast to the period of excess moisture or inferred above-normal rainfall (C and D) illustrated by the positive cumulative NDVI anomaly over the 2008-2009 growing season. Such comparisons are useful in examining drought severity from year to year across different regions and are especially useful in drought and agricultural real-time monitoring applications.

These and other studies have demonstrated the utility of AVHRR NDVI data in drought monitoring and mapping and also illustrated the contribution that 


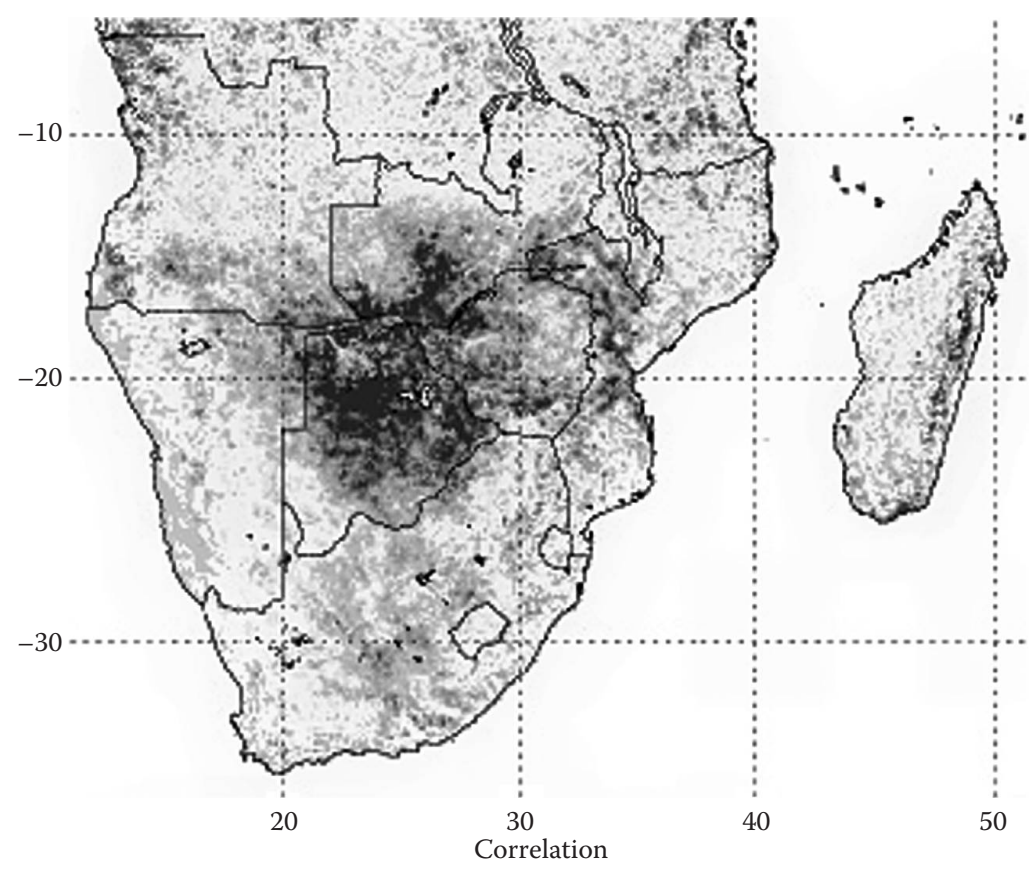

(A) $\quad \begin{array}{lllllllllllllllllll} & -8 & -7 & -6 & -5 & -4 & -3 & -2 & -1 & 0 & 1 & 2 & 3 & 4 & 5 & 6 & 7+\end{array}$

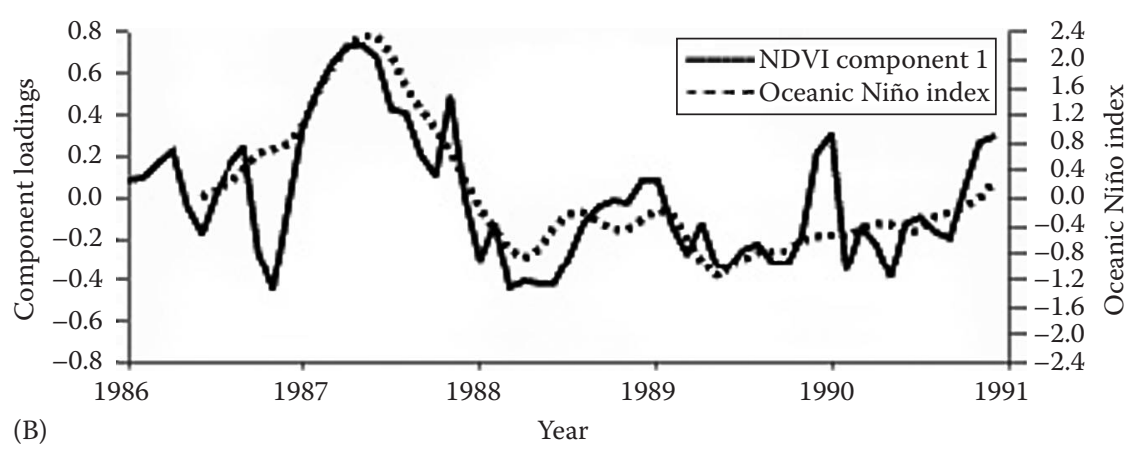

FIGURE 2.6 (See color insert.) Principal component analysis results of monthly NDVI anomaly time series for southern Africa for the period 1986-1990, showing the drought spatial pattern in (A) and the associated temporal loadings for the first principal component in (B). This component accounts for $9.73 \%$ of the total variance of the anomaly time series. The temporal loadings (B) represent the correlation between each image in the time series with the component spatial pattern in the map (A). The component loadings show a positive correlation with the drought (negative) spatial component pattern in the map (A) between late 1986 and late 1987 and negative correlation (wetter or greener than normal conditions) between 1988 and 1990 with the spatial component pattern (A). This component pattern is related to interannual variability rainfall associated with the ENSO phenomenon. The temporal loadings are highly correlated $(r=0.80)$ with ENSO that is represented by the Oceanic Niño Index (ONI). (Reconstructed after Anyamba, A. and Eastman, J.R., Int. J. Rem. Sens., 17, 2533, 1996.) 

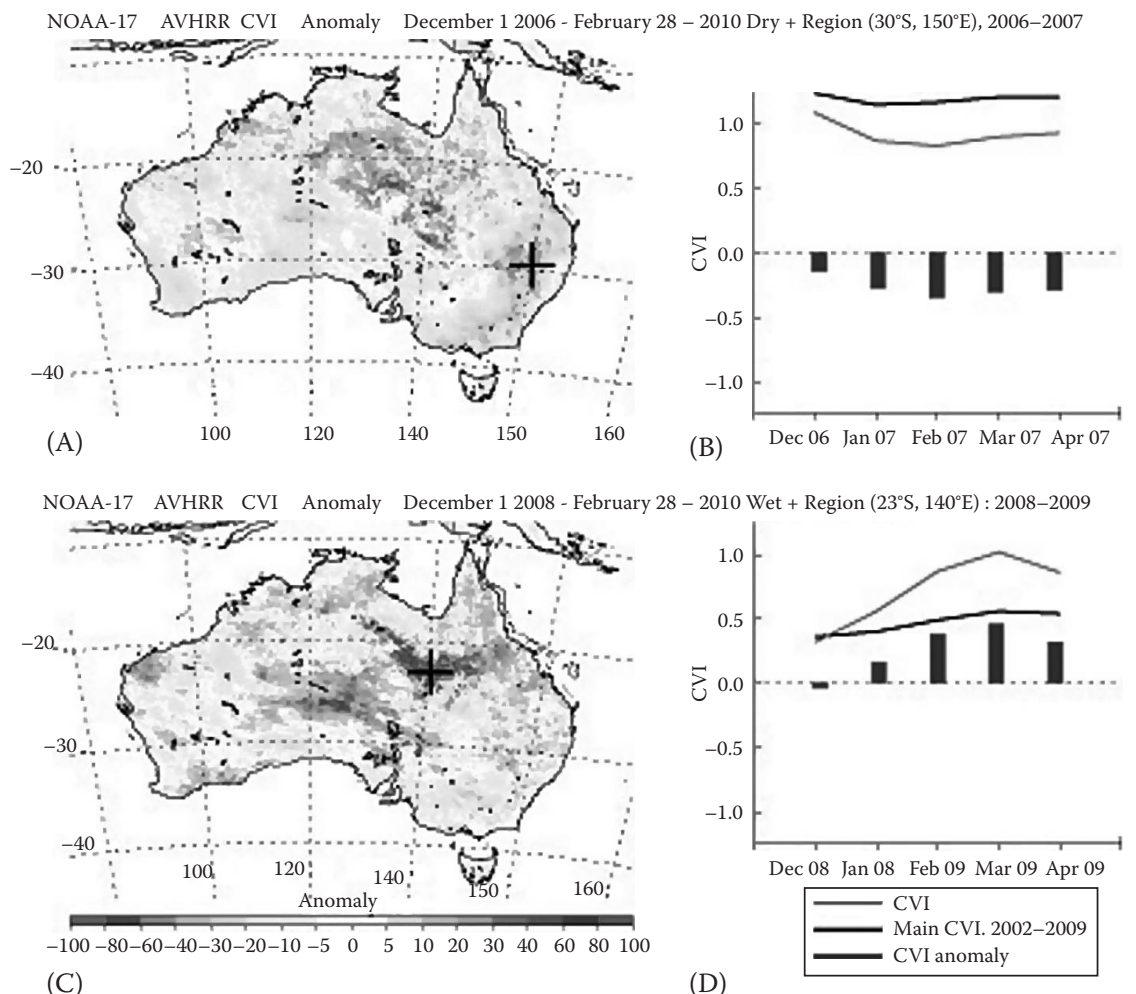

FIGURE 2.7 (See color insert.) Cumulative NDVI anomalies (CVI) for Australia, showing the cumulative nature of drought from December 2006 to 2007 (A) and the wetter/greenerthan-normal conditions from December 2008 to February 2009 (C). Cumulative time-series profiles are shown for a drought location (B) and a wet location (D).

these time-series data have made toward a better understanding of the processes that lead to drought and the land-surface response to short-term and long-term climate variability.

\subsection{INSTRUMENTAL CHALLENGES AND NEXT-GENERATION NDVI SENSORS}

Although the AVHRR NDVI data have provided unprecedented information for drought and environmental monitoring, challenges remain for data usage. First, the AVHRR has a large pixel footprint ranging from 1 to $8 \mathrm{~km}$ spatial resolution $(8 \mathrm{~km}$ for most available global data sets). Second, the instrument uses wide spectral bandwidths that are subject to atmospheric interference (specifically aerosols and water vapor) and therefore not ideally suited for vegetation monitoring. Finally, given that AVHRR is an optical sensor, major cloud contamination problems remain, especially in the tropical regions (Holben, 1986; Fensholt et al., 2009). For most areas of the world, the growing season is persistently cloudy, with cloud cover present $30 \%$ 
or more of the time. As a result, it is not possible to monitor the dynamics of landsurface conditions at a high temporal frequency in such areas.

Presently, NDVI data from the Moderate Resolution Imaging Spectroradiometer (MODIS) on board NASA's Terra (AM) and Aqua (PM) are now available and widely used in drought monitoring and agricultural applications ( $\mathrm{Gu}$ et al., 2008; Becker-Reshef et al., 2010; Pittman et al., 2010). MODIS offers a generational improvement over AVHRR. The narrower spectral bandwidths for the "red" band (band 1: 620-670 nm), which has increased chlorophyll sensitivity, and the NIR band (band 2: $841-876 \mathrm{~nm}$ ), which is less influenced by water-vapor absorption, are marked advancements over AVHRR. Coupled with state-of-the-art atmospheric correction techniques, the MODIS spectral bands offer improved sensitivity to vegetation conditions/changes and provide data at several temporal $(8,16$, and 32 days) and spatial $(250,500$, and $1000 \mathrm{~m}$ ) resolutions (Huete et al., 2002; Justice and Townshend, 2002). However, even with these improvements, cloud cover is still an impediment in some areas. Currently, there are various attempts to employ data from the geostationary Meteosat Second Generation (MSG) satellite to fill coverage gaps (Fensholt et al., 2006a) and to exploit radar/microwave systems (uninhibited by clouds) for alternative remote sensing observations of land-surface conditions. The MSG can provide cloud-free imagery over cloudcontaminated areas in the tropics with a composite period of less than 5 days because of high-frequency imaging of the instrument (every $15 \mathrm{~min}$ ), and therefore cloud-free NDVI can be generated over areas with persistent cloud cover (e.g., West Africa) during the growing season (Fensholt et al., 2006b,c). Radar also provides cloud-free imaging capabilities that can be particularly useful in studying vegetation dynamics of northern dense canopy forests (Ranson and Sun, 1994) and the Amazon (Hess et al., 1995). Some studies have begun to investigate the use of these data for drought and vegetation monitoring in a research mode, but have yet to transition the data and techniques to operational production and application. Another method of cloud screening uses Fourier analysis and empirical mode decomposition (EMD) to derive cloud-free NDVI data by approximating NDVI values of cloudy pixels (Roerink et al., 2000; Pinzon et al., 2005). However, such techniques are better suited to long time-series research data sets than to real-time operational applications because they require intensive analysis of baseline data for processing a corrected data set.

Another challenge is the intersatellite instrument calibration among the series of AVHRR instruments that have been used over the past 29+ years to develop a historical NDVI time series. On average, the AVHRR sensors have a lifespan of 5 years (see Figure 2.8, Table 2.2). Therefore, the existing long-term NDVI data set is made of a compilation of observations from several different AVHRR instruments with different calibration characteristics. The orbital decay and intersensor differences between these instruments introduce bias in the derived NDVI time series, which must be compensated for in order to develop a long-term data set appropriate for environmental monitoring. There have been several attempts to produce a coherent long-term NDVI time series, including the GIMMS NDVI version g data set (Pinzon et al., 2005; Tucker et al., 2005) (shown in Figure 2.8), and the Long-Term Data Records (LTDR) project (Pedelty et al., 2007). Biases that emerge in using AVHRR 

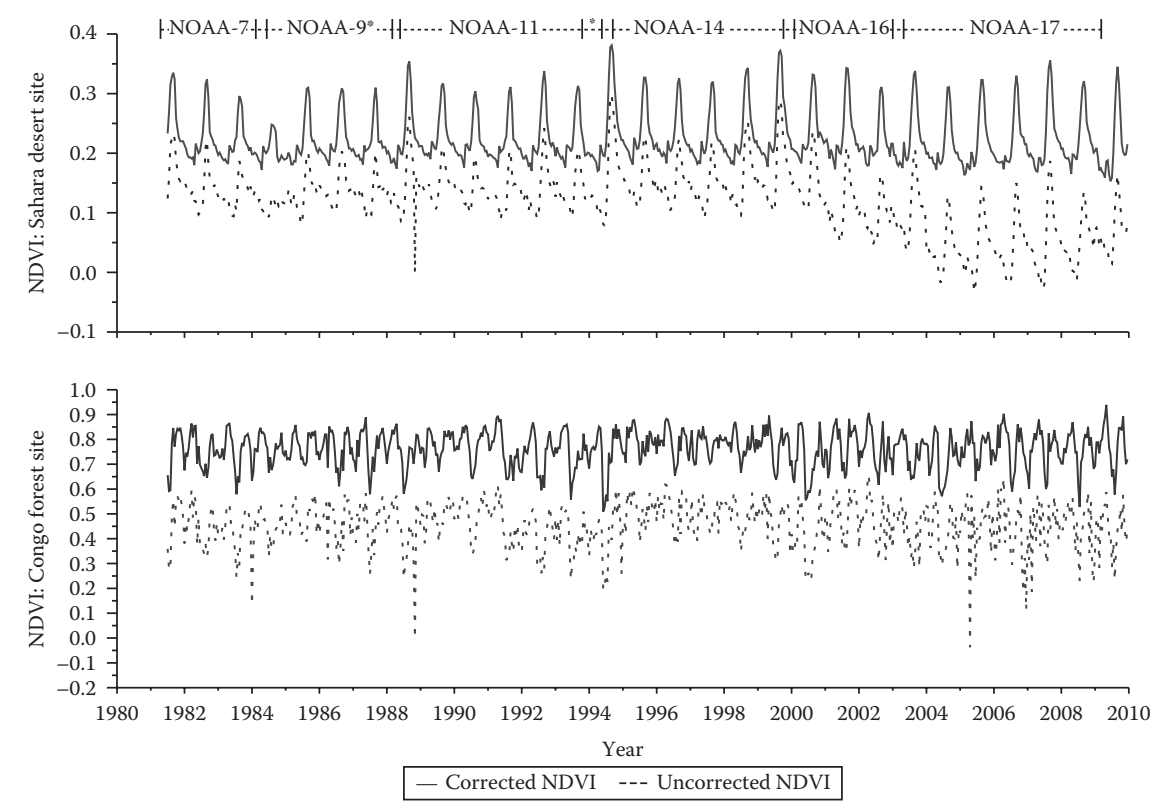

FIGURE 2.8 Uncorrected (dotted line) and corrected (thick line) NDVI time-series data plots for a Sahel site and Congo Forest site. The EMD method was applied to the original NDVI data (uncorrected), which eliminates satellite discontinuities (e.g., in 1984, 1988, and 1994) as well as spurious trends. (From Pinzon, J.E. et al., Satellite time series correction of orbital drift artifacts using empirical mode decomposition, in EMD and Its Applications, eds. N.E. Huang and S.S.P. Shen, Part II, Chap. 10, World Scientific Publishers, Singapore.)

instruments from the different sensing platforms are apparent in Figure 2.8 for two different land surfaces: the desert of the semiarid Sahel and Congo forest. Following the uncorrected data series, the discontinuities or dramatic step-change (decrease or increase) in the NDVI time series at different points in time (e.g., 1984, 1988, and 1995 ) indicate the change from one AVHRR instrument to another. Each instrument has slightly different calibration characteristics; once in orbit, it usually takes a couple of months for a given instrument to be tested and cleared for operational use. Over time, the AVHRR is subject to orbital drift (e.g., 1992-1994 Congo forest site) - hence the degradation of sensor performance.

The GIMMS and LTDR data sets are attempts to remove and correct the effects of the aforementioned factors by creating a standardized and coherent time series, as shown in Figure 2.8. Using the lessons learned from MODIS (i.e., processing techniques, calibration, atmospheric correction, and directional effect determination), the LTDR project applies these methods to the overlapping AVHRR and MODIS periods. The results gleaned from the overlap period are then applied to the AVHRR data preceding the MODIS instrument to produce higher-quality AVHRR data products. However, these data sets are more appropriate for historical, retrospective studies rather than near-real-time operational activities (such as drought monitoring) because of the 1- to 3-year time lag between data updates. 
Although MODIS data are available, delays in data processing render them inadequate for real-time drought monitoring. MODIS is classified as a science mission, and, therefore, its data processing chain was not designed for operational use. To help overcome this problem, the Land Atmosphere Near real-time Capability for EOS (LANCE) is providing near-real-time (<less than $3 \mathrm{~h}$ from observation) access to processed products such as eMODIS from USGS EROS. These real-time products are used for drought monitoring by FEWS and for VegDRI. In addition, MODIS data from LANCE are utilized for forest threat early warning (USFS Eastern Forest Environmental Threat Assessment Center: http://www.forestthreats.org/) and Global Land Agricultural Monitoring (GLAM: http://www.pecad.fas.usda.gov/glam.cfm), which is a joint project between GSFC and USDA Foreign Agricultural Service (FAS) to monitor global agricultural conditions.

\subsection{CONCLUSIONS AND THE FUTURE}

The AVHRR instrument was originally designed solely for meteorological applications. A significant and unintended use for these data has been land-surface monitoring through use of the NDVI. The AVHRR NDVI data set from July 1981 to present has created a record of land-surface conditions that has never been available before to the scientific and environmental monitoring communities. As illustrated by the many examples in this chapter, and this book as a whole, these data will continue to be important to a wide range of users, including the drought monitoring community. In the short term, there will be continued availability of NDVI data from the NOAA series of satellites (NOAA-18 and NOAA-19) and the Meteorological Operational polar-orbiting satellite (MetOp) AVHRR series from the European community that also fly AVHRR instruments. In addition, the availability of data since 2001 from MODIS has ensured that there is a redundancy in NDVI data availability. MODIS also provides a more spatially detailed global record of NDVI observations (250 and $500 \mathrm{~m}$ ). These observations are better suited for a full suite of applications that require more landscape-level observations than the AVHRR $1 \mathrm{~km} / 8 \mathrm{~km}$ data could provide. The follow-on satellites in the Joint Polar Satellite System (JPSS) with the Visible/ Infrared Imager/Radiometer Suite (VIIRS) instruments (first launched in October 2011) will guarantee that the history of coarse- to medium-scale global remote sensing data will continue to be available to support operational activities such as drought monitoring. However, commitments by governments and space agencies to continue these missions into the future and lessen the turn-around time between science missions are of paramount importance to the drought-monitoring community and other societal applications.

\section{ACKNOWLEDGMENTS}

We acknowledge the contributions of the Earth Sciences Directorate, NASA/HQ, and USAID through the FEWS NET and FAO of the United Nations for support during the early phase of the development of the NDVI data set by the GIMMS group. 
Current support is provided by the USDA FAS and Agricultural Research Service and Department of Defense Global Emerging Infections Surveillance and Response System (GEIS). We thank Kathrine Collins, Jennifer Small, Edwin Park, Robert Mahoney, Ronald J. Eastman, and Jorge E. Pinzon for contributing illustrations and figures, Kathrine Collins for dedicating her time to assist in many ways on research for this chapter, and Judith Strohmaier for other logistical assistance. We appreciate the assistance of reviewers in making this chapter possible.

\section{REFERENCES}

Anyamba, A. and J.R. Eastman. 1996. Interannual variability of NDVI over Africa and its relation to El Niño/Southern Oscillation. International Journal of Remote Sensing 17:2533-2548.

Anyamba, A. and C.J. Tucker. 2005. Analysis of Sahelian vegetation dynamics using NOAAAVHRR NDVI data from 1981-2003. Journal of Arid Environments 63:596-614.

Anyamba, A., C.J. Tucker, and J.R. Eastman. 2001. NDVI anomaly patterns over Africa during the 1997/98 ENSO warm event. International Journal of Remote Sensing 22:1847-1859.

Anyamba, A., C.J. Tucker, and R. Mahoney. 2002. From El Niño to La Niña: Vegetation response patterns over East and Southern Africa during the 1977-2000 period. Journal of Climate 15:3096-3103.

Asrar, G., M. Fuchs, E.T. Kanemasu, and J.L. Hatfield. 1984. Estimating absorbed photosynthetically active radiation and leaf area index from spectral reflectance in wheat. Agronomy Journal 76:300-306.

Asrar, G., E.T. Kanemasu, R.D. Jackson, and P.J. Pinter. 1985. Estimation of total above-ground phytomass production using remotely sensed data. Remote Sensing of Environment 17:211-220.

Asrar, G., E.T. Kanemasu, G.P. Miller, and R.L. Weiser. 1986. Light interception and leaf area estimates from measurements of grass canopy reflectance. IEEE Transactions on Geoscience and Remote Sensing GE24:76-82.

Azzali, S. and M. Menenti. 2000. Mapping vegetation-soil-climate complexes in southern Africa using Fourier analysis of NOAA-AVHRR NDVI data. International Journal of Remote Sensing 21:973-996.

Barbosa, H.A., A.R. Huete, and W.E. Baethgen. 2006. A 20-year study of NDVI variability over the Northeast Region of Brazil. Journal of Arid Environments 67:288-307.

Baret, F. and G. Guyot. 1991. Potentials and limits of vegetation indices for LAI and APAR assessment. Remote Sensing of Environment 35:161-173.

Becker-Reshef, I., C. Justice, M. Sullivan, E. Vermote, C. Tucker, A. Anyamba, J. Small, E. Pak, E. Masuoka, J. Schmaltz, M. Hansen, K. Pittman, C. Birkett, D. Williams, C. Reynolds, and B. Doorn. 2010. Monitoring global croplands with coarse resolution earth observations: The Global Agriculture Monitoring (GLAM) Project. Remote Sensing 2:1589-1609.

Brown, J.F., B.C. Reed, M.J. Hayes, D.A. Wilhite, and K. Hubbard. 2002. A prototype drought monitoring system integrating climate and satellite data. Pecora 15/Land Satellite Information IV/ISPRS Commission I/FIEOS 2002 Conference Proceedings, Denver, CO, November 10-14.

Brown, J.F., B.D. Wardlow, T. Tadesse, M.J. Hayes, and B.C. Reed. 2008. The Vegetation Drought Response Index (VegDRI): A new integrated approach for monitoring drought stress in vegetation. GIScience and Remote Sensing 45:16-46.

Burgan, R.E. and R.A. Hartford. 1993. Monitoring vegetation greenness with satellite data. Gen. Tech. Rep. DNT-297, U.S. Department of Agriculture, Forest Service, Intermountain Research Station, Ogden, UT. 
Burgan, R.E., R.A. Hartford, and J.C. Eidenshink. 1996. Using NDVI to assess departure from average greenness and its relation to fire business. General Technical Report INTGTR-333, U.S. Department of Agriculture, Forest Service, Intermountain Research Station, Ogden, UT.

Deering, D.W., J.W. Rouse Jr., R.H. Haas, and J.A. Schell. 1975. Measuring "forage production" of grazing units from Landsat MSS data. 10th International Symposium on Remote Sensing of Environment Proceedings, Ann Arbor, MI, October 6-10.

Dyer, M.I. and D.A. Crossley. 1986. Coupling of ecological studies with remote sensing: Potentials at four biosphere reserves in the United States. Publication 9504, U.S. State Department's U.S. Man and the Biosphere Program, Washington, DC.

Eastman, R.R. and M. Fulk. 1993. Long sequence time series evaluation using standardized principal components. Photogrammetric Engineering and Remote Sensing 59:991-996.

Eidenshink, J.C. and R.H. Hass. 1992. Analyzing vegetation dynamics of land systems with satellite data. GeoCarto International 1:53-61.

Fensholt, R., A. Anyamba, S. Stisen, I. Sandholt, E. Pak, and J. Small. 2006a. Comparisons of compositing period length for vegetation index data from polar-orbiting and geostationary satellites for the cloud-prone region of West Africa Special Issue: Cloud-prone and Rainy areas Remote Sensing (CARRS). Photogrammetric Engineering and Remote Sensing 73:297-310.

Fensholt, R., T.T. Nielsen, and S. Stisen. 2006b. Evaluation of AVHRR PAL and GIMMS 10-day composite NDVI time series products using SPOT-4 vegetation data for the African continent. International Journal of Remote Sensing 27:2719-2733.

Fensholt, R., K. Rasmussen, T.T. Nielsen, and C. Mbow. 2009. Evaluation of earth observation based long-term vegetation trends-Intercomparing NDVI time series trend analysis consistency of Sahel from AVHRR GIMMS, Terra MODIS and SPOT VGT data. Remote Sensing of Environment 113:1886-1898.

Fensholt, R., I. Sandholt, S. Stisen, and C.J. Tucker. 2006c. Analyzing NDVI for the African continent using the geostationary Meteosat second generation SEVIRI sensor. Remote Sensing of Environment 101:212-229.

Funk, C.M., M.D. Dettinger, J.C. Michaelsen, J.P. Verdin, M.E. Brown, M. Barlow, and A. Hoell. 2008. Warming of the Indian Ocean threatens eastern and southern African food security but could be mitigated by agricultural development. Proceedings of the National Academy of Science USA 105:11081-11086.

Gallo, K.P. 1990. Satellite derived vegetation indices: A new climatic variable? Proceedings of the Symposium on Global Change Systems, Special Sessions on Climate Variations and Hydrology, American Meteorological Society, Anaheim, CA, February 5-9, pp. 133-137.

Gates, D.M., H.J. Keegan, J.C. Schleter, and V.P. Weldner. 1965. Spectral properties of plants. Applied Optics 4:11-20.

Gatlin, J.A., R.J. Sullivan, and C.J. Tucker. 1984. Considerations of and improvements to large-scale vegetation monitoring. IEEE Transactions on Geoscience and Remote Sensing GE22:496-502.

Gu, Y., E. Hunt, B. Wardlow, J.B. Basara, J.F. Brown, and J.P. Verdin. 2008. Evaluation of MODIS NDVI and NDWI for vegetation drought monitoring using Oklahoma Mesonet soil moisture data. Geophysical Research Letters 35:L22401.

Hardisky, M.A., F.C. Daiber, C.T. Roman, and V. Klemas. 1984. Remote sensing of biomass productivity of a salt marsh. Remote Sensing of Environment 16:91-106.

Hatfield, J.L., G. Asrar, and E.T. Kanemasu. 1984. Intercepted photosynthetically active radiation in wheat canopies estimated by spectral reflectance. Remote Sensing of Environment 14:65-76.

Hess, L.L., J.M. Melack, S. Filoso, and Y. Wang. 1995. Delineation of inundated area and vegetation along the Amazon floodplain with the SIR-C synthetic-aperture radar. IEEE Transactions on Geoscience and Remote Sensing 33:896-904. 
Hielkema, J.U., J. Roffey, and C.J. Tucker. 1986. Assessment of ecological conditions associated with the 1980/1981 desert locust plague upsurge in West Africa using environmental satellite data. International Journal of Remote Sensing 7:1609-1622.

Hiernaux, P.H.Y. and C.O. Justice. 1986. Suivi du developpement vegetal au cours de l'ete 1984 dans le Sahel Malien. International Journal of Remote Sensing 7:1515-1532.

Holben, B.N. 1986. Characteristics of maximum-value composite images from temporal AVHRR data. International Journal of Remote Sensing 7:1417-1434.

Holben, B.N. and R.S. Fraser. 1984. Red and near-infrared sensor response to off-nadir viewing. International Journal of Remote Sensing 5:145-160.

Holben, B.N., D. Kimes, and R.S. Fraser. 1986. Directional reflectance response in AVHRR red and near-IR bands for three cover types and varying atmospheric conditions. Remote Sensing of Environment 19:213-236.

Huete, A.R. 1988. A soil-adjusted vegetation index (SAVI). Remote Sensing of Environment 25:295-309.

Huete, A., K. Didan, T. Miura, and E. Rodriguez. 2002. Overview of the radiometric and biophysical performance of the MODIS vegetation indices. Remote Sensing of Environment 83:195-213.

Huete, A.R., R.D. Jackson, and D.F. Post. 1985. Spectral response of a plant canopy with different soil backgrounds. Remote Sensing of Environment 17:37-53.

Huete, A.R. and C.J. Tucker. 1991. Investigation of soil influences in AVHRR red and near-infrared vegetation index imagery. International Journal of Remote Sensing 12:1223-1242.

Hutchinson, C.F. 1991. Use of satellite data for famine early warning in sub-Saharan Africa. International Journal of Remote Sensing 12:1405-1421.

Janowiak, J.E. 1988. An investigation of interannual rainfall variability in Africa. Journal of Climate 1:240-255.

Ji, L. and A.J. Peters. 2004. A spatial regression procedure for evaluating the relationship between AVHRR-NDVI and climate in the northern Great Plains. International Journal of Remote Sensing 25:297-311.

Justice, C.O. and J.R.G. Townshend. 2002. Special issue on the moderate resolution imaging spectroradiometer (MODIS): A new generation of land surface monitoring. Remote Sensing of Environment 83:1-2.

Justice, C.O., J.R.G. Townshend, B.N. Holben, and C.J. Tucker. 1985. Analysis of the phenology of global vegetation using meteorological satellite data. International Journal of Remote Sensing 6:1271-1318.

Karnieli, A., N. Agam, R.T. Pinker, M. Anderson, M.L. Imhoff, G.G. Gutman, N. Panov, and A. Goldberg. 2010. Use of NDVI and land surface temperature for drought assessment: Merits and limitations. Journal of Climate 23:618-633.

Karnieli, A., M. Bayasgalan, Y. Bayarjargal, N. Agam, S. Khudulmur, and C.J. Tucker. 2006. Comments on the use of the Vegetation Health Index over Mongolia. International Journal of Remote Sensing 27:2017-2024.

Karnieli, A., M. Shachak, H. Tsoar, E. Zaady, Y. Kaufman, A. Danin, and W. Porter. 1996. The effect of microphytes on the spectral reflectance of vegetation in semiarid regions. Remote Sensing of Environment 2:88-96.

Kimes, D.S. 1983. Dynamics of directional reflectance factor distributions for vegetation canopies. Applied Optics 22:1364-1372.

Kimes, D.S., B.N. Holben, C.J. Tucker, and W.W. Newcomb. 1984. Optimal directional view angles for remote sensing missions. International Journal of Remote Sensing 5:877-891.

Knipling, E.B. 1970. Physical and physiological basis for the reflectance of visible and near infrared radiation from vegetation. Remote Sensing of Environment 1:155-159.

Kogan, E.N. 1990. Remote sensing of weather impacts on vegetation. International Journal of Remote Sensing 11:1405-1419. 
Kogan, E.N. 1995a. Application of vegetation index and brightness temperature for drought detection. Advances in Space Research 15:91-100.

Kogan, E.N. 1995b. Droughts of the late 1980s in the United States as derived from NOAA polar-orbiting satellite data. Bulletin of the American Meteorological Society 76:655-668.

Kogan, F. and J. Sullivan. 1993. Development of global drought-watch system using NOAA/ AVHRR data. Advances in Space Research 13:219-222.

Kumar, M. and J.L. Monteith. 1982. Remote sensing of plant growth. In Plants and the Daylight Spectrum, ed. H. Smith, pp. 133-144. London, U.K.: Academic Press Inc.

Lambin, E.F. and D. Ehrlich. 1996. The surface temperature-vegetation index space for land cover and land-cover change analysis. International Journal of Remote Sensing $17: 463-478$.

Liu, W.T. and F.N. Kogan. 1996. Monitoring regional drought using the Vegetation Condition Index. International Journal of Remote Sensing 17:2761-2782.

Liu, W.T. and R.I. Negron Juarez. 2001. ENSO drought onset prediction in northeast Brazil using NDVI. International Journal of Remote Sensing 22:3483-3501.

Los, S.O., G.J. Collatz, L. Bounoua, P.J. Sellers, and C.J. Tucker. 2001. Global inter-annual variations in sea surface temperature and land surface vegetation, air temperature, and precipitation. Journal of Climate 14:1535-1549.

Lotsch, A., M.A. Friedl, B.T. Anderson, and C.J. Tucker. 2005. Response of terrestrial ecosystems to recent Northern Hemisphere drought. Geophysical Research Letters 32:L06705.

Loveland, T.R., J.W. Merchant, J.F. Brown, and D.O. Ohlen. 1991. Development of a landcover characteristics database for the conterminous U.S. Photogrammetric Engineering and Remote Sensing 57:1453-1463.

Martiny, N., P. Camberlin, Y. Richard, and N. Philippon. 2006. Compared regimes of NDVI and rainfall in semi-arid regions of Africa. International Journal of Remote Sensing 27:5201-5223.

McVicar, T.R. and P.N. Bierwirth. 2001. Rapidly assessing the 1997 drought in Papua New Guinea using composite AVHRR imagery. International Journal of Remote Sensing 22:2109-2128.

Mennis, J. 2001. Exploring relationships between ENSO and vegetation vigor in the south-east USA using AVHRR data. International Journal of Remote Sensing 22:3077-3092.

Myneni, R.B., F.B. Hall, P.J. Sellers, and A.L. Marshak. 1995. The interpretation of spectral vegetation indices. IEEE Transactions on Geoscience and Remote Sensing 33:481-486.

Myneni, R.B., S.O. Los, and C.J. Tucker. 1996. Satellite-based identification of linked vegetation index and sea surface temperature anomaly areas from 1982-1990 for Africa, Australia and South America. Geophysical Research Letters 23:729-732.

Nicholson, S.E. 1989. African drought: Characteristics, casual theories, and global teleconnections. In Understanding Climate Change, eds. A. Berger, R.E. Dickinson, and J.W. Kidson, pp. 79-100. Washington, DC: American Geophysical Union.

Nicholson, S.E., M.L. Davenport, and A.R. Malo. 1990. A comparison of the vegetation response to rainfall in the Sahel and East Africa, using normalized difference vegetation index from NOAA AVHRR. Climatic Change 17:209-242.

NOAA Satellite and Information Service. NOAA Polar Orbiter Data User's Guide, Silver Spring, MD. http://www.ncdc.noaa.gov/oa/pod-guide/ncdc/docs/podug/figures.htm (accessed on December 12, 2011).

NOAA Satellite and Information Service, Silver Spring, MD, http://www.oso.noaa.gov/history/first-launched.htm (accessed on December 12, 2011).

Norwine, J. and D.H. Greegor. 1983. Vegetation classification based on Advanced Very High Resolution Radiometer (AVHRR) satellite imagery. Remote Sensing of Environment 13:69-87. 
Pedelty, J., S. Devadiga, E. Masuoka, M. Brown, J. Pinzon, C. Tucker, D. Roy, J. Ju, E. Vermote, S. Prince, J. Nagol, C. Justice, C. Schaaf, J. Liu, J. Privette, and A. Pinheiro. 2007. Generating a long-term land data record from the AVHRR and MODIS instruments. Proceedings of Geoscience and Remote Sensing Symposium IGARRS, New York.

Peters, A.J., E.A. Walter-Shea, L. Ji, A. Vina, M. Hayes, and M.D. Svoboda. 2002. Drought monitoring with NDVI-Based Standardized Vegetation Index. Photogrammetric Engineering and Remote Sensing S 68:71-75.

Pinzon, J.E, M.E. Brown, and C.J. Tucker. 2005. Satellite time series correction of orbital drift artifacts using empirical mode decomposition. In EMD and Its Applications, eds. N.E. Huang and S.S.P. Shen, Part II, Chap. 10. Singapore: World Scientific Publishers.

Pittman, K., M.C. Hansen, I. Becker-Reshef, P.V. Potapov, and C.O. Justice. 2010. Estimating global cropland extent with multi-year MODIS data. Remote Sensing 2:1844-1863.

Prince, S.D. and C.J. Tucker. 1986. Satellite remote sensing of rangelands in Botswana II: NOAA AVHRR and herbaceous vegetation. International Journal of Remote Sensing 7:1555-1570.

Ranson, K.J. and G. Sun. 1994. Mapping biomass of a northern forest using multifrequency SAR data. IEEE Transactions on Geoscience and Remote Sensing 32:388-396.

Richardson, A.J. and C.L. Wiegand. 1977. Distinguishing vegetation from soil background information. Photogrammetric Engineering and Remote Sensing 43:1541-1552.

Roerink, G.J., M. Menenti, and W. Verhoef. 2000. Reconstructing cloud free NDVI composites using Fourier analysis of time series. International Journal of Remote Sensing 21:1911-1917.

Rouse Jr., J.W., R.H. Haas, J.A. Schell, and D.W. Deering. 1974a. Monitoring vegetation systems in the Great Plains with ERTS. Paper presented at the 3rd ERTS-1 Symposium, Greenbelt, MD.

Rouse Jr., J.W., R.H. Haas, J.A. Schell, D.W. Deering, and J.C. Harlan. 1974b. Monitoring the vernal advancement and retrogradation (green wave effect) of natural vegetation. NASA/GSFC Type III Final Report, Greenbelt, MD.

Schneider, S.R., D.F. McGinnis, and J.A. Gatlin. 1981. Use of NOAA AVHRR visible and near-infrared data for land remote sensing. NOAA Technical Report NESS 84 for the NOAA National Earth Satellite Service, Washington, DC.

Sellers, P.J. 1985. Canopy reflectance, photosynthesis, and transpiration. International Journal of Remote Sensing 6:1335-1372.

Sellers, P.J. 1987. Canopy reflectance, photosynthesis, and transpiration II: The role of biophysics in the linearity of their interdependence. Remote Sensing of Environment 21:143-183.

Singh, R.P., S. Roy, and F. Kogan. 2003. Vegetation and temperature condition indices form NOAA AVHRR data for drought monitoring over India. International Journal of Remote Sensing 24:4393-4402.

Song, X., G. Saito, M. Kodama, and H. Sawada. 2004. Early detection system of drought in East Asia using NDVI from NOAA/AVHRR data. International Journal of Remote Sensing 25:3105-3111.

Steven, M.D., P.V. Biscoe, and K.W. Jaggard. 1983. Estimation of sugar beet productivity from reflection in the red and near-infrared spectral bands. International Journal of Remote Sensing 4:325-334.

Stone, T.A., P. Schlesinger, R.A. Houghton, and G.M. Woodwell. 1994. A map of the vegetation of South America based on satellite imagery. Photogrammetric Engineering and Remote Sensing 60:541-551.

Tateishi, R. and M. Ebata. 2004. Analysis of phenological change during 1982-2000 Advanced Very High Resolution Radiometer (AVHRR) data. International Journal of Remote Sensing 25:2287-2300.

Tateishi, R. and K. Kajiwara. 1992. Global land cover monitoring by AVHRR NDVI data. Earth Environment 7:4-14. 
Townshend, J.R.G., T.E. Goff, and C.J. Tucker. 1985. Multi-temporal dimensionality of images of normalized difference vegetation index at continental scales. IEEE Transactions on Geoscience Remote Sensing GE-23:888-895.

Townshend, J.R.G., C.O. Justice, and V. Kalb. 1987. Characterization and classification of South American land cover types using satellite data. International Journal of Remote Sensing 8:1189-1207.

Tucker, C.J. 1979. Red and photographic infrared linear combinations for monitoring vegetation. Remote Sensing of Environment 8:127-150.

Tucker, C.J. 1996. History of the use of AVHRR data for land applications. In Advances in the Use of NOAA AVHRR Data for Land Applications, eds. G. D'Souza, A.L. Belward, and J. Malingreau, pp. 1-19. Dordrecht, the Netherlands: Kluwer Academic Publishers.

Tucker, C.J., J.U. Hielkema, and J. Roffey. 1985c. The potential of satellite remote sensing of ecological conditions for survey and forecasting desert-locust activity. International Journal of Remote Sensing 6:127-138.

Tucker, C.J., C.O. Justice, and S.D. Prince. 1986. Monitoring the grasslands of the Sahel 1984-1985. International Journal of Remote Sensing 7:1571-1581.

Tucker, C.J., W.W. Newcomb, S.O. Los, and S.D. Prince. 1991. Mean and inter-year variation of growing-season normalized difference vegetation index for Sahel 1981-1989. International Journal of Remote Sensing 12:1133-1135.

Tucker, C.J., J.E. Pinzon, M.E. Brown, D.A. Slayback, E.W. Pak, R. Mahoney, E. Vermote, and N. El Saleous. 2005. An extended AVHRR 8-km NDVI dataset compatible with MODIS and SPOT vegetation NDVI data. International Journal of Remote Sensing 26:4485-4498.

Tucker, C.J. and P.J. Sellers. 1986. Satellite remote sensing of primary production. International Journal of Remote Sensing 7:1395-1416.

Tucker, C.J., J.R.G. Townshend, and T.E. Goff. 1985a. African land-cover classification using satellite data. Science 227:369-375.

Tucker, C.J., C.L. Vanpraet, E. Boerwinkel, and A. Gaston. 1983. Satellite remote sensing of total dry matter production in the Senegalese Sahel: 1980-1984. Remote Sensing of Environment 13:461-474.

Tucker, C.J., C.L. Vanpraet, M.J. Sharman, and G. Van Ittersum. 1985b. Satellite remote sensing of total herbaceous biomass production in the Senegalese Sahel: 1980-1984. Remote Sensing of Environment 17:233-249.

Unganai, L.S. and F.N. Kogan. 1998. Drought monitoring and corn yield estimation in southern Africa from AVHRR data. Remote Sensing of Environment 63:219-232.

Verdin, J., C. Funk, R. Klaver, and D. Roberts. 1999. Exploring the correlation between Southern Africa NDVI and Pacific sea surface temperatures: Results for the 1998 maize growing season. International Journal of Remote Sensing 20:2117-2124.

Wang, Q., S. Adiku, J. Tenhunen, and A. Granier. 2005. On the relationship of NDVI with leaf area index in a deciduous forest site. Remote Sensing of Environment 94:244-255.

Wardlow, B.D., M.J. Hayes, M.D. Svoboda, T. Tadesse, and K.H. Smith. 2009. Sharpening the focus on drought-New monitoring and assessment tools at the National Drought Mitigation Center. Earthzine. http://www.earthzine.org/2009/03/30/sharpeningthe-focus-on-drought-\%E2\%80\%93-new-monitoring-and-assessment-tools-at-thenational-drought-mitigation-center/ (accessed June 20, 2011).

Wiegand, C.L. and A.J. Richardson. 1984. Leaf area, light interception, and yield estimates from spectral components analysis. Agronomy Journal 76:543-548.

Woolley, J.T. 1971. Reflectance and transmittance of light by leaves. Plant Physiology 47:656-662. 

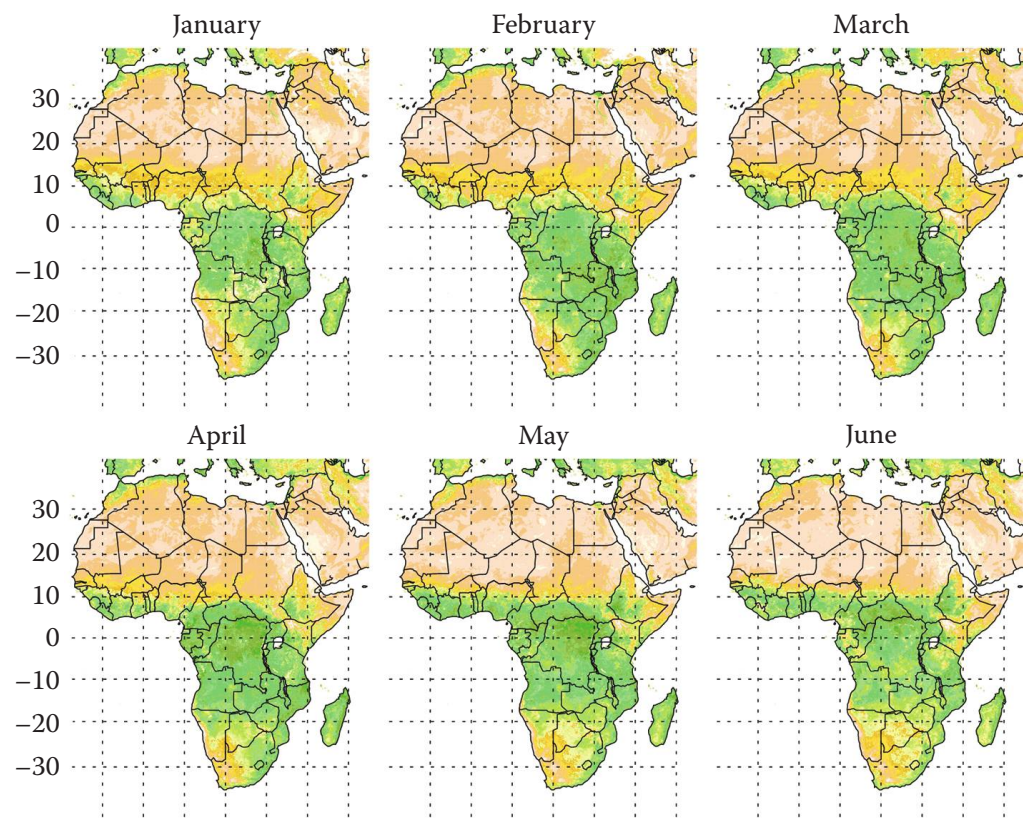

July
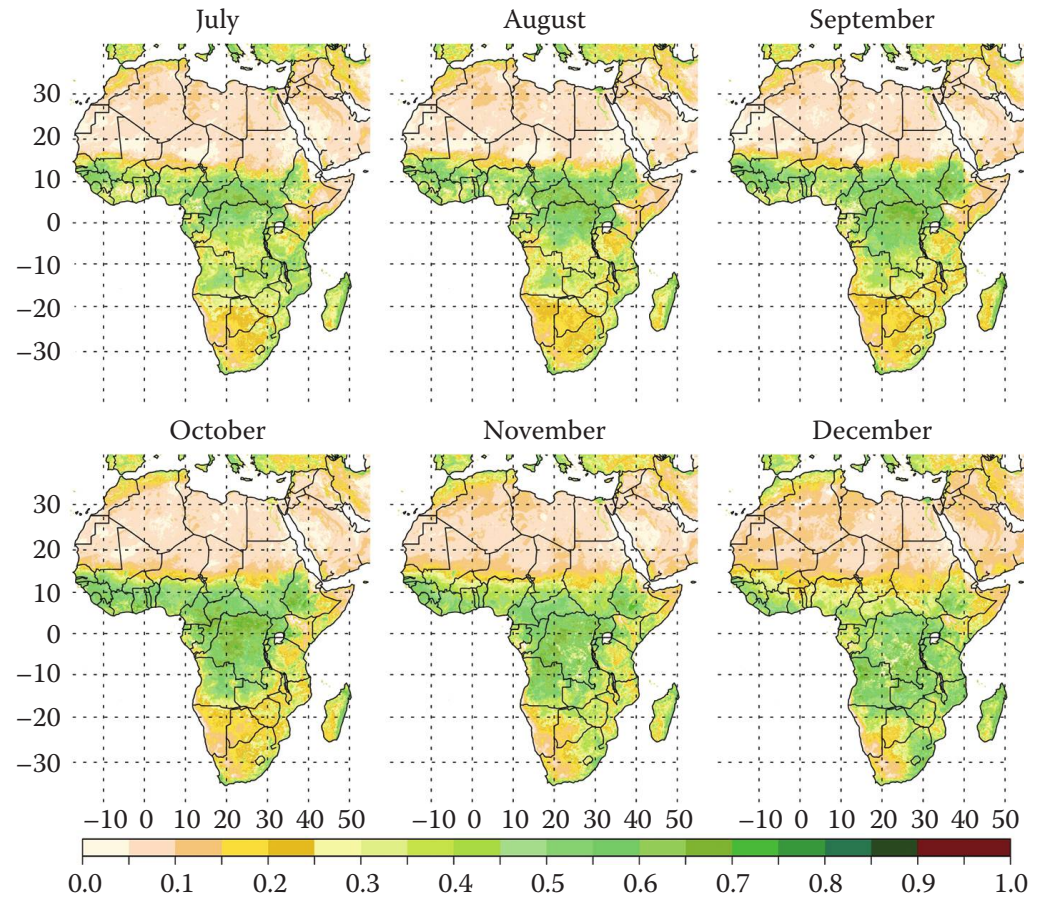

FIGURE 2.2 Example of typical monthly NDVI time-series data for Africa and the Middle East. In general, areas of high NDVI or high vegetation density are represented in shades of green while areas of low NDVI/low vegetation density such as semiarid lands and Sahara and Arabian deserts are shown in shades of yellow to brown. The patterns change seasonally from January through December. (Data produced by GIMMS Group at NASA/GSFC, Greenbelt, MD.) 


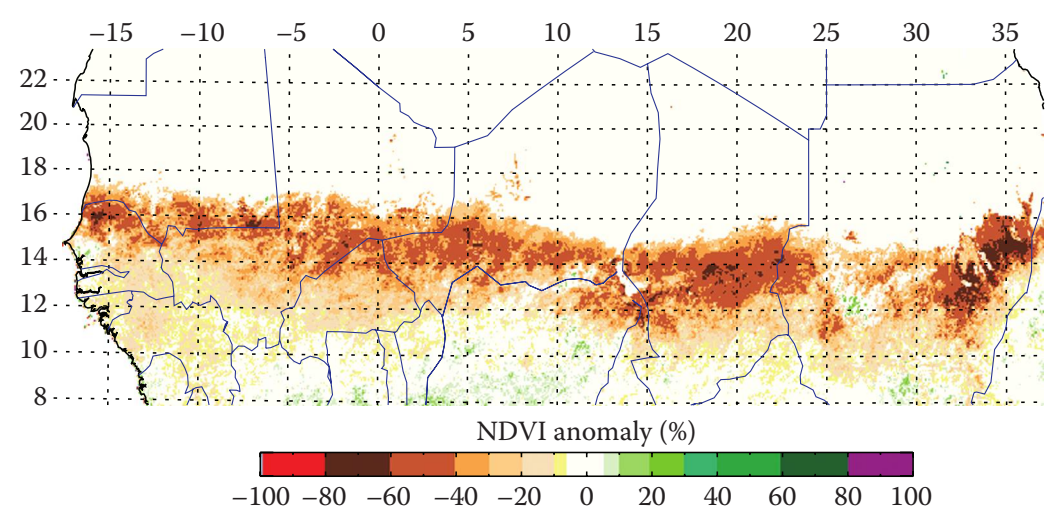

FIGURE 2.5 Growing season (July-October) NDVI anomaly for the Sahel region showing the large areal extent of the Sahelian drought in 1984. Before AVHRR NDVI data became available, such regional-to-continental mapping of drought extent and patterns was not possible. (Adapted from Anyamba, A. and Tucker, C.J., J. Arid Environ., 63, 596, 2005.)

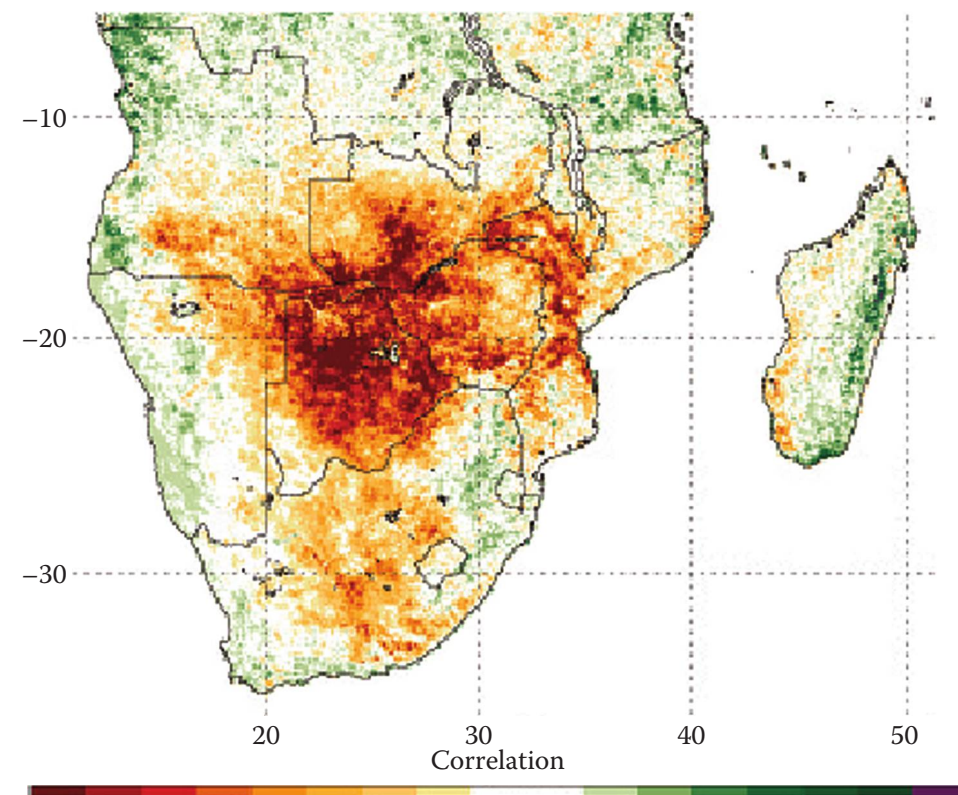

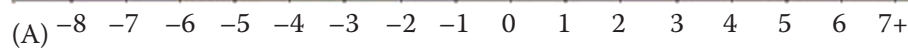

FIGURE 2.6 Principal component analysis results of monthly NDVI anomaly time series for southern Africa for the period 1986-1990, showing the drought spatial pattern in (A) and the associated temporal loadings for the first principal component in (B). This component accounts for $9.73 \%$ of the total variance of the anomaly time series. The temporal loadings (B) represent the correlation between each image in the time series with the component spatial pattern in the map (A). The component loadings show a positive correlation with the drought (negative) spatial component pattern in the map (A) between late 1986 and late 1987 and negative correlation (wetter or greener than normal conditions) between 1988 and 1990 with the spatial component pattern (A). This component pattern is related to interannual variability rainfall associated with the ENSO phenomenon. The temporal loadings are highly correlated $(r=0.80)$ with ENSO that is represented by the Oceanic Niño Index (ONI). (Reconstructed after Anyamba, A. and Eastman, J.R., Int. J. Rem. Sens., 17, 2533, 1996.) 

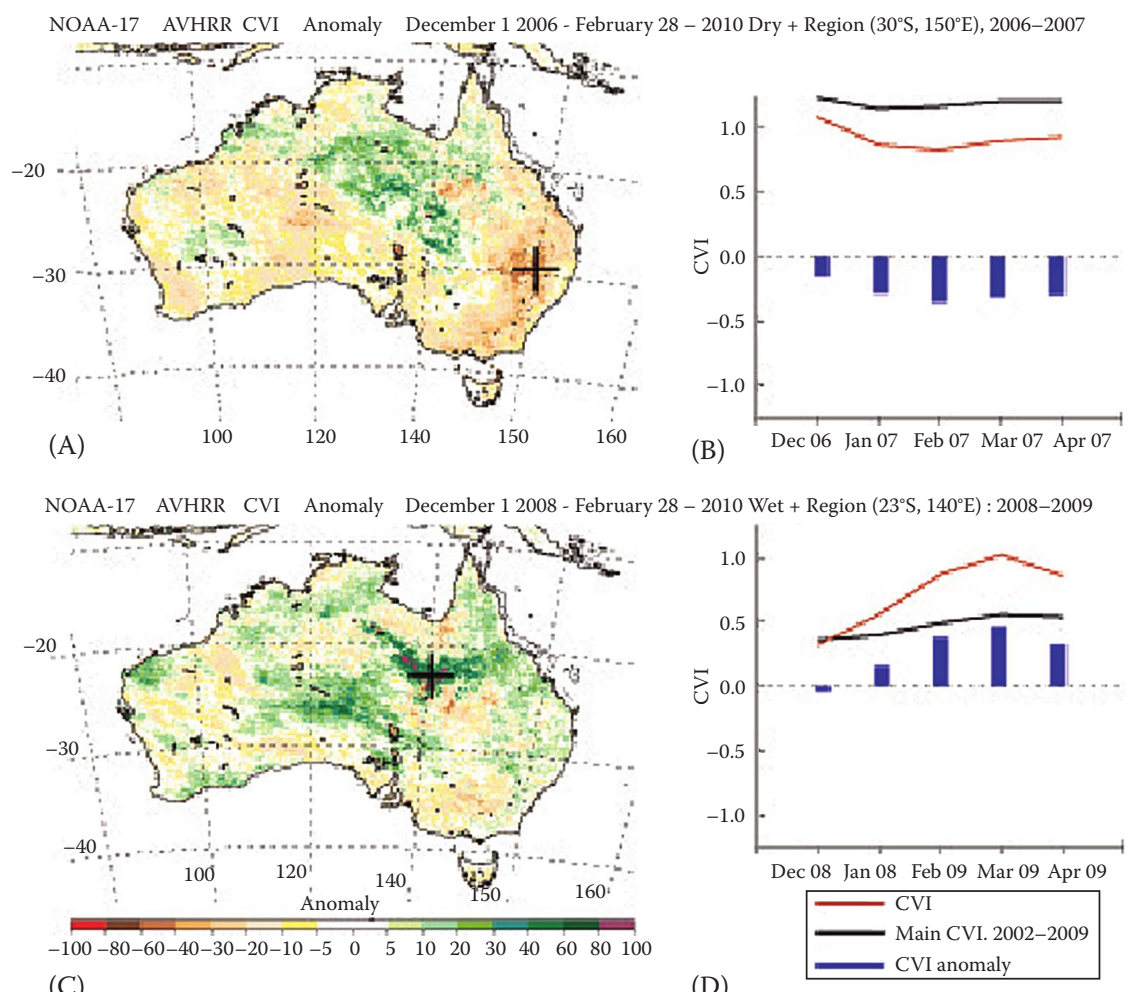

(C)

(D)

FIGURE 2.7 Cumulative NDVI anomalies (CVI) for Australia, showing the cumulative nature of drought from December 2006 to 2007 (A) and the wetter/greener-than-normal conditions from December 2008 to February 2009 (C). Cumulative time-series profiles are shown for a drought location (B) and a wet location (D). 